\title{
Sensing of single electrons using micro and nano technologies: a review
}

\author{
Jubayer Jalil ${ }^{1,2}$, Yong Zhu ${ }^{1,2}$, Chandima Ekanayake ${ }^{1}$, Yong Ruan ${ }^{3}$
}

${ }^{1}$ School of Engineering, Griffith University, Gold Coast, QLD 4222, Australia

${ }^{2}$ Queensland Micro and Nanotechnology Centre, Griffith University, Nathan, QLD 4111, Australia

${ }^{3}$ Department of Precision Instruments, Tsinghua University, Beijing P. R. China

Corresponding Author Emails: y.zhu@griffith.edu.au, ruanyong@mail.tsinghua.edu.cn

\section{Contents}

Abstract

1. Introduction

2. Mesoscopic single-electron transistor (SET) electrometer

3. Resonant electrometer

3.1 NEMS based electrometer

3.2 MEMS based electrometer

4. Vibrating-reed electrometer

5. Summary and perspectives

References

\section{Abstract}

During the last three decades, the remarkable dynamic features of microelectromechanical systems (MEMS) and nanoelectromechanical systems (NEMS), and advances in solid-state electronics hold much potential for the fabrication of extremely sensitive charge sensors. These sensors have a broad range of applications, such as those involving the measurement of ionization radiation, detection of bio-analyte and aerosol particles, mass spectrometry, scanning tunneling microscopy, and quantum computation. Designing charge sensors (also known as charge electrometers) for electrometry is deemed significant because of the sensitivity and resolution issues in the range of micro- and nano-scales. This article reviews the development of state-of-the-art micro- and nano-charge sensors, and discusses their technological challenges for practical implementation. 


\section{Keywords}

electrometer, charge sensor, resolution, single-electron transistor (SET), MEMS/NEMS resonator, vibrating-reed

\section{Introduction}

The sensing of single electrons, in terms of electrostatic charge or miniature current, is measured by a device called a charge sensor (which is also known as a charge electrometer). Contacting (direct) and non-contacting (no physical or electrical contact) measurements are two different methods that are used to detect electrostatic charge. Charge sensors or charge electrometers are widely used for direct measurement of electric charge or extremely small current [1]-[2]. On the other hand, a number of non-contacting electrostatic voltmeters and electric field meters have been used for many years to measure the surface charge of any test object [3]-[8]. Highly sensitive charge electrometers are prevalent in many diverse applications. These include: mass spectrometry; surface charge analysis; ionization current measurement in ionization chambers as well as radiation or particle detection of nuclear studies; and various applications of powder technology and aerosol science [9]-[12]. Such electrometers are also used in a number of precision applications, such as tunneling microscopy; ultrafine particles measurement; bimolecular and electrochemical charge detection; and even space exploration [13]-[17].

In the early twentieth century, Millikan demonstrated the quantitative electromechanical measurement of electrostatic charge ( 1 electron $\approx 1.60217733 \times 10^{-19} \mathrm{C}$ ) by using an "oil drop" experiment [18]. In that experiment, he charged a tiny drop of oil and measured how strong an applied electric field had to be in order to stop the oil drop from falling. By varying the charge on different drops, he was able to find the charge of a single electron. Before the advent of modern active electrometers, such as early valves (vacuum tubes) and semiconductor transistors, different types of passive electrometers were widely used. These are described elsewhere [2], [19]. Of these, the gold-leaf electroscope, Coulumb's electrometer, and Kelvin's quadrant electrometer were the most popular. Nowadays, compared to these classical electrometers, high resolution charge electrometers (together with electronic devices and signal conditioning circuitries) are exploited for translating electrostatic charge or very tiny current into electrical signals. Traditionally, the charge of a small object or piece of material is measured by placing it in a Faraday cup or pail (or 
Faraday cage) along with a sensitive electrometer. This cup acts as a shielded sensing electrode of the electrometer, and consequently, the object induces an equal magnitude of charge, but of an opposite sign on the surface of the cup (inner cup) [20]-[21].

The Keithley 6517A (a commercial solid-state electrometer) is well-known for its minimum resolution of $10 \mathrm{fC}(\approx 63,000$ electrons) [22]. However, for bespoke scientific applications, this resolution is insufficient to meet scientific needs. One of the reasons for the low resolution and moderate sensitivity of this instrument is due to the preamplifier's built-in input noise, i.e. preamp noise. In sensitive charge measurement techniques, it is inevitable to avoid the noise caused by this pre-amplifier. Operational amplifier based readout circuits (used in existing electrometers), such as a transimpedance amplifier (TIA), a charge amplifier, and a resistive gain amplifier, exhibit three common electrical noises: Johnson noise, shot noise and flicker noise in different bandwidths of operation [23]-[24]. Due to these noise effects, the sensitivity and the resolution of these kinds of commercial electrometers are limited. Hence, requirement of low-noise, high sensitive charge sensors or electrometers is nowadays essential for precise measurement of electrostatic charge. Currently, charge sensing can be carried out using cutting-edge nanoelectronic devices, such as field-effect transistors (FETs), single-electron transistors (SETs), and quantum pointcontacts (QPCs). Additionally, the charge sensors can be implemented by resonance type MEMS/NEMS devices and micromachined vibrating-reed type devices due to the advancement of nanomaterials and semiconductor processes.

In this paper, we review the charge detection mechanism of miniature electrometers, specifically the mesoscopic single-electron transistor (SET); the NEMS and MEMS based resonant sensors; and the MEMS based vibrating-reed sensors. This review will allow us to determine the practical attributes of each mechanism in different technologies by focusing on the resolution and noise characteristics.

\section{Mesoscopic Single-Electron Transistor (SET) Electrometer}

The single-electron tunneling transistor (SETT) or single-electron transistor (SET) is deemed the most fundamental nanoscale single-electron device (SED) due to its capability of manipulating just one electron [25]-[27]. It gains its name by utilizing the quantum 
phenomenon of tunneling to measure and control the movement of single electrons inside a solid-state circuit. Due to the exceptional progression of nanoelectronics in the last two decades, SETs as solid-state electrometers are out-performing conventional metal-oxide semiconductor field-effect transistors (MOSFETs) based electrometers by three orders of magnitude in terms of charge resolution [28]-[29]. A three-terminal SET includes a source, a drain, a gate, and a minuscule channel region known as conductive island or quantum dot (QD) or Coulumb blockade island (made by metals or compound semiconductors or carbon nanotubes or graphene) [30]-[33]. This conductive island is isolated from the source and drain by two tunnel junctions or barriers (e.g. $\mathrm{SiO}_{2}$ ) (figure 1). Employing a small voltage across a tunnel junction of a SET, it behaves like a tunnel capacitor. However, electrons tunnel through this barrier, which can be explained intrinsically by a quantum mechanics phenomenon illustrated in [26]-[27], [31].

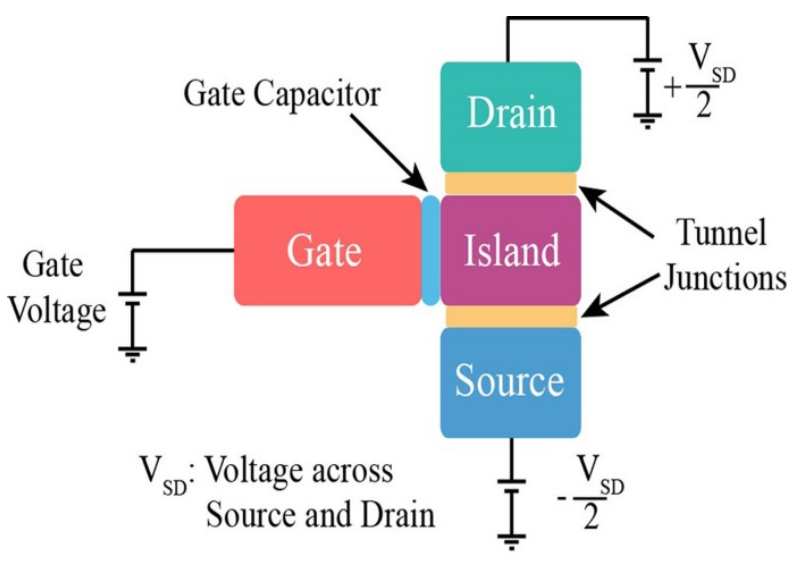

(a)

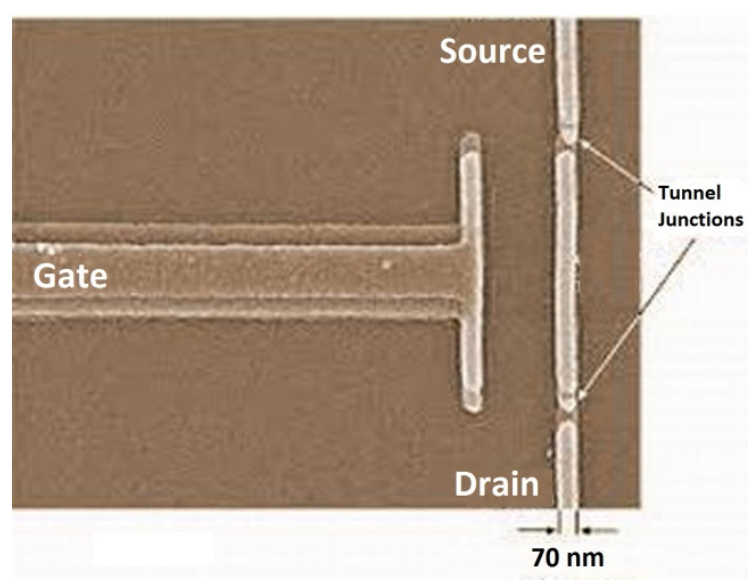

(b)

Figure 1. (a) Block diagram of SET as a charge electrometer (b) scanning-electron micrograph image of $\mathrm{Al}$ based SET [30]

If a constant voltage is applied to a tunnel junction of a SET, periodic current pulses are produced. The small total capacitance of the Coulomb blockade and the discreteness of the electric charge instigate the current to behave as a periodic function of the gate charge with a period of one electron charge. This occurrence results in Coulomb blockade oscillations (CBO). By adding a positive or negative charge directly to the island, the CBO characteristic is shifted by one period along the gate voltage axis. These gate voltage $\left(\delta V_{g}\right)$ changes, corresponding to sub-electron variations of $q_{i n}$, cause a measurable change in source-drain current $\left(I_{S D}\right)$ through modulating the transconductance, $g_{m}=\delta I_{S D} / \delta V_{g}$. Thus, to achieve 
maximum gate voltage sensitivity, conventional SETs are biased to a point of maximum $g_{m}$. In this sense, the SET is considered a highly sensitive, miniaturized electrometer, which can easily sense a fraction of the elementary (sub-single electron) charge by the change in its characteristics (if the charge is placed close to the conducting island or QD) [31].

Krupenin et al. demonstrated conventional Al-SET electrometers with charge resolution down to $8 \times 10^{-6} \mathrm{e} / \sqrt{ } \mathrm{Hz}$ at $10 \mathrm{~Hz}$ [34]. The resolution of $8 \times 10^{-6} \mathrm{e} / \sqrt{ } \mathrm{Hz}$ means that the charge of $8 \times 10^{-6} \mathrm{e}$ on the SET gate of the electrometer can be detected against the noise in a 1-S measurement. The charge resolution of DC-SET can be represented as $\delta q / \sqrt{\Delta f}=\left[\sqrt{2 e I_{D S}}\right.$. $\left.\sqrt{S_{I}(0)}\right] / G_{m}$. Here, $G_{m}$ is charge gain, $S_{I}(0)$ is the normalized zero-frequency noise [35]. High resolution of the sensor can be achieved by reducing the total noise spectral density and by improving the sensitivity of the device. Although this resolution was high, it was evaluated at a low frequency, where the flicker noise predominates in the system hiding small signals. In most experiments involving the SET, the noise at low frequencies is dominated by the device itself, whereas external sources set the noise limit for frequencies above the $\mathrm{kHz}$ regime. Owing to the small bandwidth and this extra noise contribution, the predicted charge resolution is difficult to achieve. Besides the flicker noise, two other types of noise affect the performance of SETs: shot noise and amplifier noise [36]. The resolution of this nanotransistor is mostly be limited by the shot noise generated when electrons tunnel across the tunnel barriers. The shot noise is observed in a two-junction structure without a gate. In the SET, the noise is believed to be caused by a small, two-level system, either in close proximity to the conducting island or inside a tunnel barrier.

To overcome the flicker noise problems and detect fast charge fluctuations, a technique that incorporates the Al-based SET into a radio-frequency resonant circuit (i.e. LC tank circuit denoted as RF-SET) is better than conventional DC-SETs [29], [32], [37]-[38]. By using this technique, a charge resolution of $1.2 \times 10^{-5} \mathrm{e} / \sqrt{ } \mathrm{Hz}$ was recorded at a signal frequency of 100 $\mathrm{MHz}$ [29]; on the other hand, using a resolution bandwidth of $15 \mathrm{kHz}$, Brenning et al. measured a high charge resolution of $1.9 \times 10^{-6} \mathrm{e} / \sqrt{\mathrm{Hz}}$ at a temperature of $4.2 \mathrm{~K}$ [38]. Instead of measuring the output current or voltage, this reflectometry technique monitored the damping of the resonant circuit. It has the advantage of substantially reducing low-frequency flicker noise due to the high operating frequency. A single-wall carbon nanotube (SWNT) RF-SET based electrometer proposed by Tang et al. achieved a charge resolution of $4.8 \mathrm{x}$ 
$10^{-4} \mathrm{e} / \sqrt{ } \mathrm{Hz}$ at $30 \mathrm{~Hz}$ bandwidth, as shown in figure 2 [32]. The transistor's sensitivity performance was improved by reducing the two-junction area and island size compared to its Al based RF-SET counterpart. Angus et al. developed a silicon based RF-SET and achieved an even better resolution of $10 \times 10^{-6} \mathrm{e} / \sqrt{ } \mathrm{Hz}$ using at $15 \mathrm{MHz}$ bandwidth [39]. Employing $\mathrm{Si} / \mathrm{SiGe}$ quantum dots (QDs) with a radio frequency superconducting single-electron transistor (RF-SSET) detected excellent charge resolution of $4 \times 10^{-6} \mathrm{e} / \sqrt{\mathrm{Hz}}$ at $1 \mathrm{kHz}$ bandwidth, with an SNR of $27.5 \mathrm{~dB}$ [40]. The charge resolution of RF-SETs is determined using following expression: $\delta q=\Delta q_{r m s} /\left[10^{S N R / 20} \cdot \sqrt{2 B}\right]$. Here, $\Delta q_{r m s}$ is the applied root mean square gate charge, $B$ is the resolution bandwidth of the spectrum analyzer, $\sqrt{ } 2$ accounts for the fact that there are two side peaks, and SNR is the signal to noise ratio in $\mathrm{dB}$ [38].

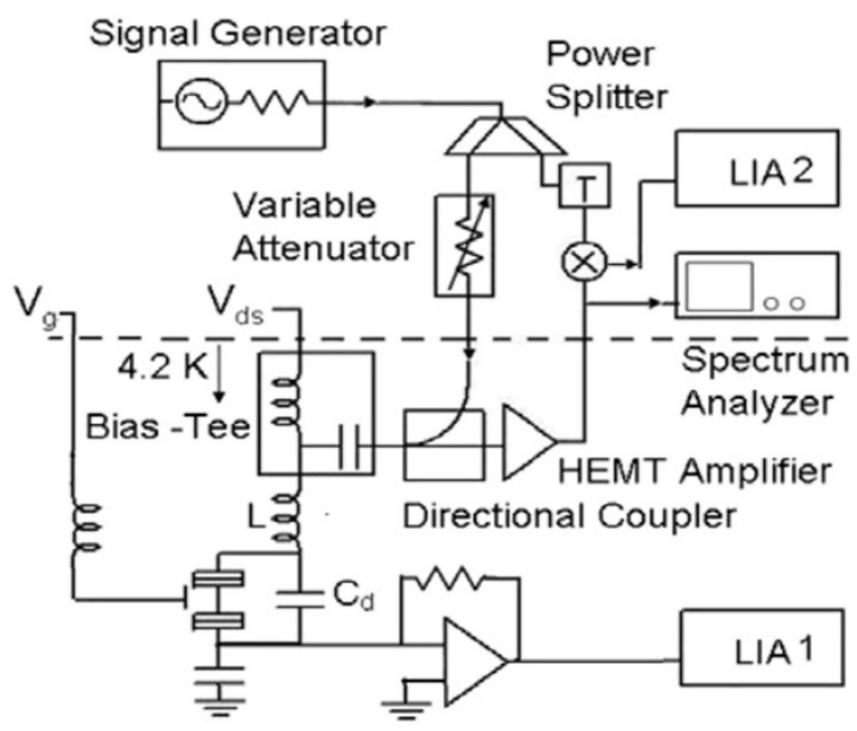

Figure 2. Schematic diagram of the RF-SET measurement setup [32]

In SETs, the tunneling of electrons through the junction barrier depends on the electrostatics of the system. Electrons can tunnel into the island only if the charging energy associated with adding the electrons to the island is overcome. The electrostatic charging energy of a single island SET is defined as $E_{c}=e^{2} /\left(2 C_{\text {total }}\right)$; where, $C_{\text {total }}$ is the summation of two junction capacitances and one gate capacitance [31]. It is essential that this energy is overcome before an electron can tunnel onto the island, and the external applied bias $\left(V_{d s}\right)$ provides the energy for tunneling. To observe single electron tunneling, low temperature operation is required. Otherwise, the tunneling process can be activated thermally without external bias because of 
thermal energy $K_{B} T$. At room temperature (300K), the thermal energy could be sufficiently higher than the electrostatic charging energy $E_{c}$, thereby reducing the charge resolution.

There are two strategies to stop the tunneling process caused by the thermal effect. The first strategy is to reduce the thermal energy by lowering the temperature. For example, restricting the cryogenic temperature regime of SETs can make the thermal energy $K_{B} T$ below the charging energy $E_{c}$. However, cryogenic temperature operation needs bulky and costly equipment and has been one of the main technological obstacles affecting the advancement and proliferation of these devices as practical charge sensors [41]. The second strategy is to increase the charging energy $E_{c}$ to be more than thermal energy $K_{B} T$ at room temperature for the room temperature operation. As $E_{c}=e^{2} /\left(2 C_{\text {total }}\right)$, the charging energy can be increased by reducing $C_{\text {total }}$ to significantly small values, for example around atto-farad range or even less. To achieve $1 \mathrm{aF}$ capacitance, the island dimension is required to be reduced to less than 10 $\mathrm{nm}$. Therefore, feature size of existing electron beam lithography, optical lithography or even focus ion beam lithography need to be improved to shrink the island size of the SET, maintaining sufficient charging energy to operate at room temperature [42]. In addition, implementation of multiple tunnel junction (MTJ), i.e., serially connected multiple-island system in the SETs, is another plausible means of reducing $C_{\text {total }}$ for room temperature operation [43]-[44]. Recently, Si-FET based electrometer, one of the competitors of the SET electrometers, demonstrated by Nishiguchi et al. (fabricated on an SOI substrate), exhibits a resolution of $13 \times 10^{-4} \mathrm{e} / \sqrt{ } \mathrm{Hz}(@ 1 \mathrm{~Hz})$ at room temperature [45]. Later on, Nishiguchi et al. achieved even better resolution of $2 \times 10^{-4} \mathrm{e} / \sqrt{\mathrm{Hz}}$ with higher bandwidth of $20 \mathrm{MHz}$ at room temperature due to high SNR of $21 \mathrm{~dB}$. This was achieved by using RF-FET comprised of a nanometer-scale Si-FET with an impedance-matching circuit made up of a capacitor and an inductor by reflectometry technique [46].

Voltage gain in SETs is difficult to achieve at room temperature because the gate capacitance must be made larger than the junction capacitance while making the total capacitance small. For the SET, it is more relevant to consider the charge gain, which is a frequency dependent quantity. This charge gain is the modulation of the charge that passes through the SET divided by the change in charge on the gate. Incidentally, a charge gain of greater than one can be achieved at room temperature [47].

The background charge or offset charge problem is another important issue, which is inhibiting the extensive use of SETs [30]-[31]. In SETs, the background charge fluctuations 
result in phase shifts of the output voltage. The same kinds of charged defects are identified in nano-scale FETs. However, most of the conventional MOSFETs are not sensitive charge detectors. Therefore, the consequences of background charges are not effective for MOSFETS. One of the most effective strategies to compensate for this problem is SETs is to use the conventional MOSFETs along with SET electrometers to tune out background charges.

The large output impedance of a DC-SET (operating at room temperature) of at least $100 \mathrm{k} \Omega$ makes this transistor an intrinsically slow device. To speed up the charge measurement, conventional MOSFETs of CMOS processes should be placed as close as possible to the SETs, buffering the high output impedance of the SETs. Until a practical scheme is developed, the best way to proceed is to use the SETs only as sensitive charge sensors and perform all other functions with conventional high speed MOSFETs [31]. In order to realize high-density functional circuits using SETs, it is essential to have a reliable nano-fabrication technology that enables fabrication of a large number of SETs. Nonetheless, due to the low current drive of the SETs, hybrid SET-MOSFET circuits seem to be more useful than all-SET circuits. Thus, fabrication technology of the SETs as charge sensors, which are still in the exploratory phase at room temperature, have to be compatible with existing downscaling standard CMOS processes (e.g. $14 \mathrm{~nm}, 10 \mathrm{~nm})$.

\section{Resonant Electrometer}

In a typical MEMS/NEMS resonant sensor, the resonator's natural frequency is a function of the measurand (or disturbances or stimuli). An input disturbance typically changes the stiffness, mass and geometric shape of the resonator, thus initiating an alteration in its resonant frequency [48]-[57]. The dynamic properties of a high natural frequency, high quality factors (Q) and minuscule mass have established resonant MEMS/NEMS as improved types of sensors [58]-[63]. The natural frequency $\left(f_{x}\right)$ of the resonant device (e.g. paddle resonator) is represented as (both for translational and torsional mode) [60],

$f_{x}=\frac{1}{2 \pi} \sqrt{\frac{k_{e f f}}{m_{e f f}}}$

where, $k_{\text {eff }}=$ effective spring constant and $m_{\text {eff }}=$ effective mass or inertia of the paddle. 
In electromechanical sensing applications, coupling the resonator to the charge is achieved by applying electrostatic force (ESF) or a strain across the structure. Both the vibration (excitation) mechanism and detection mechanism are significant in the design of a resonant sensor. The vibration mechanism excites the vibrations in the structure of the resonator element, while the detection mechanism senses these vibrations in the form of frequency. Finally, the frequency of the detected vibration develops the output of the sensor in the form of voltage, as shown in figure 3. A high $Q$ factor is demanded for the MEMS/NEMS resonator based charge sensor, for which the sensor's resolution (or limit of detection) is limited by the smallest detectable change in resonant frequency. Here, the control system of the resonator can be implemented either by an open or closed loop (i.e. the signal is fed back to the drive mechanism via a sustaining amplifier).

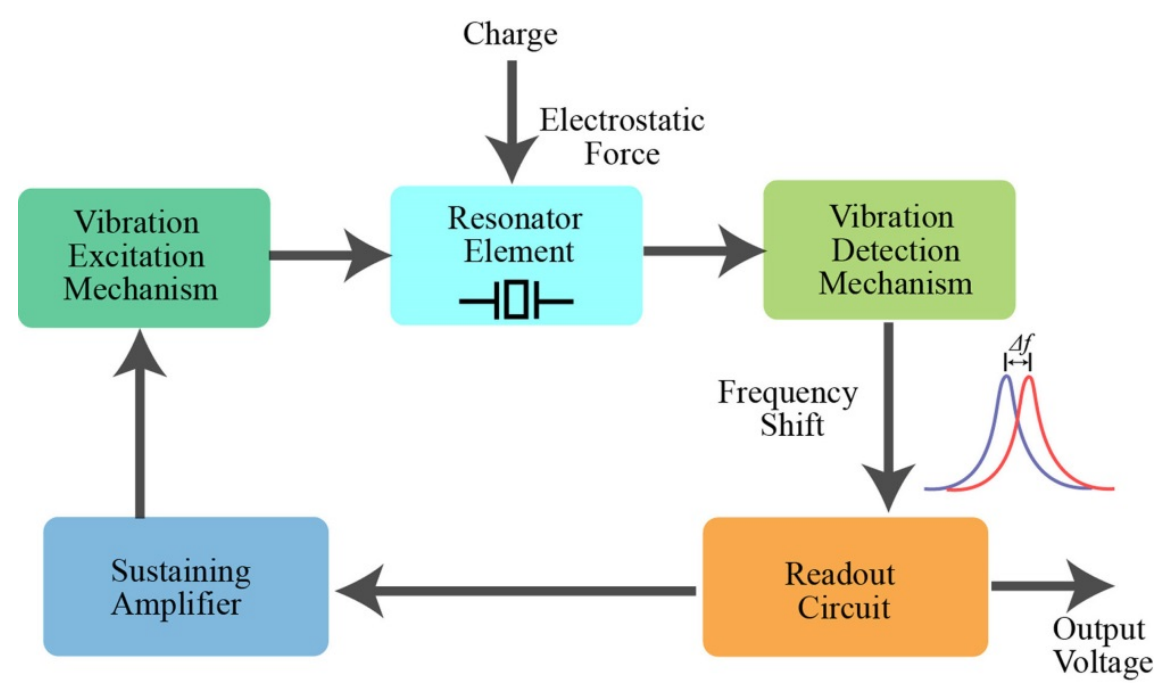

Figure 3. Block diagram of a typical resonant MEMS/NEMS charge sensor with a closedloop system

\subsection{NEMS based resonant electrometer}

Before the advent of modern electrostatic charge detection techniques (in 1785), CharlesAugustin de Coulomb introduced the first electromechanically, torsion-based electrometer [65]. After approximately 200 years, Cleland \& Roukes proposed a novel fabrication and performance analysis of a NEMS based electrometer, as shown in figure 4 [66]. Nowadays, nano-electro-mechanical systems (NEMS) have demonstrated their effectiveness in both basic science and industrial applications, due to overcoming the limitations of macro- and micro-scale devices [67]-[74]. Utilization of state-of-the-art NEMS resonant sensors (under 
conditions of vacuum and cryogenic temperature) in many scientific applications is a consequence of the ultra-small mass and size of the resonator; ultra-high natural resonance frequencies; ultra-high sensitivities for very small stimuli; ultra-low power consumption for actuation forces; and ultra-fast response time to applied forces.

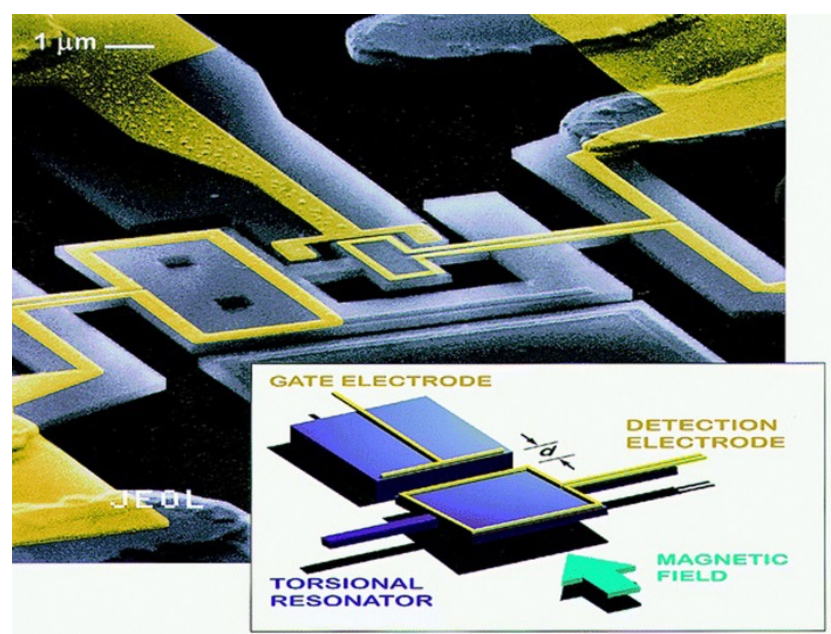

Figure 4. NEMS based charge sensor using a torsional resonator [66]

For a torsional resonator type NEMS sensor, the magnetomotive technique has been utilized for both actuation and detection [66]. While a static magnetic field is applied perpendicular to both the two-element torsional resonant structure and the current, the resonator is excited by an alternating current due to the Lorentz force. The resulting motion of the resonator through the magnetic field generates an electromotive force that is detected by the measurement circuitry. Principal components of this sensor are a double torsion mechanical resonator, two detection electrodes, and a gate electrode used to couple charge to the mechanical element. The resonator was fabricated from a single crystal Si-on-insulator substrate, with a $0.2 \mathrm{~mm}$ thick Si layer on a $0.4 \mathrm{~mm}$ insulating layer. The gold loop electrode and resonator structure are patterned using Electron Beam Lithography (EBL). This NEMS fabrication method is known as the top-down approach, using semiconductor processing technology.

Like any mechanical resonators, key figures of merit of the NEMS resonators are resonance frequency, Q factor, dimensions, geometrical structures and materials for fabrication. The resonator described in [66] is a double paddle torsional or two-element torsional resonator, which has a very high Q factor (6500) characteristic, and thus exhibits low phase noise performance. To measure a small charge, the gate electrode is biased by a charge yielding an electrostatic force (ESF). While the bias point is considered as $q_{0}$ and small changes in the 
charge are considered as $\delta q$, the bias point alters the ESF by an amount of $2 \delta q E_{0}$, where $E_{0}=$ equilibrium electric field. The principle of electrometry in this research is the change in the resonance frequency due to the charge modulation of the effective torsional spring constant; therefore, frequency modulation detection has been employed to obtain a responsivity or sensitivity measurement.

The high Q factor (i.e. less energy dissipation) of the device means it exhibits high sensitivity and high resolution [73]. To enhance the $\mathrm{Q}$ factor for achieving high resolution in resonant sensors, the damping needs to be minimised. Compared to typical MEMS dimensions of resonant sensors, this NEMS sensor has reduced structured dimensions, and thus thermoelastic damping (TED) has a negligible effect and total energy dissipation declines. The torsional element on the resonator also alleviates clamping or anchor loss to enhance the Q factor. Here, a thermal noise analysis indicates that such an NEMS resonator based electrometer exhibits resolution of the order of $10^{-6} \mathrm{e} / \sqrt{ } \mathrm{Hz}$. This very high resolution makes the device competitive with the cryogenic SET electrometers, but with important added advantages of higher temperature operation and the ability to respond over a greatly increased bandwidth. Due to a high fundamental resonance frequency of $2.61 \mathrm{MHz}$, the mechanical Johnson noise effect is insignificant in this case.

Blick et al. [75] have introduced another NEMS based charge sensor, which significantly enhances the speed of charge detection by using a clamped beam as a translational (flexural) resonator (figure 5 (a)). The device has been fabricated on an SOI substrate by a combined dry- and wet-etched process. In this nanomachined electromechanical resonator based sensor, a low-power radio frequency propagates through a suspended beam of Si covered with a thin layer of gold. This frequency sets it into vibration. With an in-plane magnetic field applied perpendicular to this straight beam, a Lorentz force perpendicular to the substrate surface is developed, which in turn sets the resonator in the motion. The two gates on both sides of the beam are biased capacitively to detune the resonator's eigen-frequency. Application of a voltage (V) between the center gates and the beam, induces a charge $(q)$ on the beam resonator via the relation: $q=\mathrm{CV}$. This essentially modifies its stiffness or spring constant under a low temperature of $4.2 \mathrm{~K}$ with ${ }^{4} \mathrm{He}$-gas pressure of approximately $10^{-2}$ bar. This results in a mechanical resonance frequency shift, $\Delta f$. When RF power steers the resonator to the verge of nonlinear amplitude vibration, optimum charge detection (maximum frequency shift) can be obtained. For a gate bias of $\pm 4 \mathrm{~V}$, a magnetic field of $12 \mathrm{~T}$, and an RF power of - 
$52.8 \mathrm{dBm}$ at $37.29 \mathrm{MHz}$, a charge detection resolution of $70 \mathrm{e} / \sqrt{\mathrm{Hz}}$ is achieved. The high resolution of $1 \mathrm{e} / \sqrt{ } \mathrm{Hz}$ can be elevated further by implementing the mixer and phase shifter used in [66]. Bunch et al. fabricated an inimitable graphene based translational resonant charge sensor exhibiting a resolution of $8 \times 10^{-4} \mathrm{e} / \sqrt{\mathrm{Hz}}$ at $300 \mathrm{~K}$ but at very low pressure of $<10^{-6}$ torr [76]. They used single- and multilayer graphene sheets by mechanically exfoliating thin sheets from graphite over trenches in $\mathrm{SiO}_{2}$ (figure 5(b)). However, at the expense of both optical/electrical actuation and optical interferometer detection, it did not achieve monumental resolution compared to [66] because of operating at room temperature.

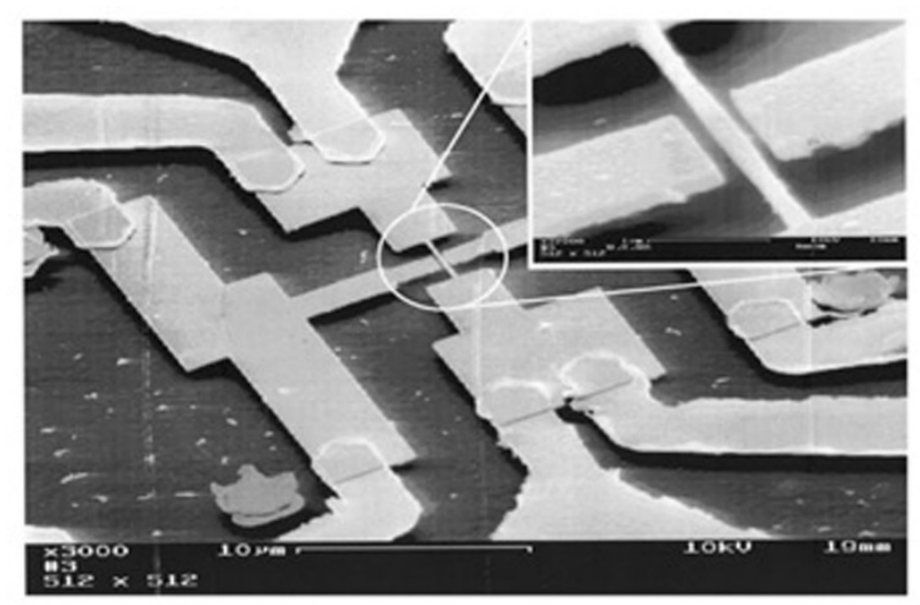

(a)

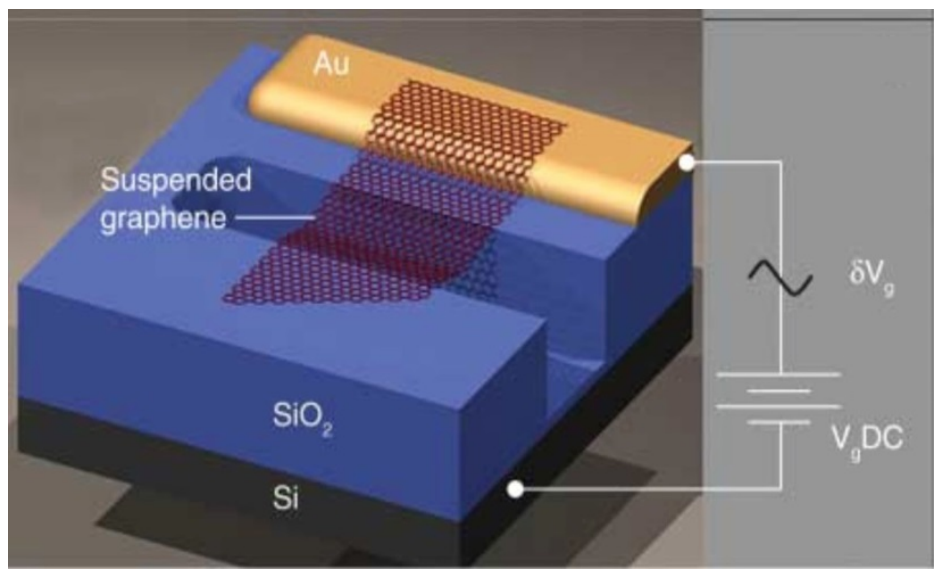

(b)

Figure 5. NEMS based charge sensor using a translational resonators (a) suspended Si [75] (b) suspended graphene [76]

The magnetomotive technique on a NEMS resonant charge sensor is advantageous for detecting charge sensitivity. Nevertheless, it is particularly limited by the requirement of comparatively strong magnetic fields (8 Tesla in [66] or 12 Tesla in [75]), which are typically 
achieved with superconducting coils at liquid helium temperature. Though these techniques are suitable for low temperature experiments of charge sensing in the fundamental research of metrology, these methods are not realistic for commercial applications. This is due to high costs, inefficient integration techniques of CMOS and NEMS technologies, large measurement setups and portability issues. In addition, the bandwidth achieved by [66] is limited to only $400 \mathrm{~Hz}$, owing to uncontrolled parasitic capacitances. Integration of mechanically flexible nano-structures with SEDs on a nanometer-scale is an exciting prospect in nano-electrometer design. Unlike conventional SETs and resonant NEMS charge sensors, a SWNT-SET resonant sensor was recently introduced by Hakkinen et al. (figure 6). This quantum electromechanical sensor has demonstrated a better resolution of $0.97 \times 10^{-6} \mathrm{e} / \sqrt{\mathrm{Hz}}$ (@ $1.3 \mathrm{kHz}$ ) at a temperature of $50 \mathrm{mK}$ [77].
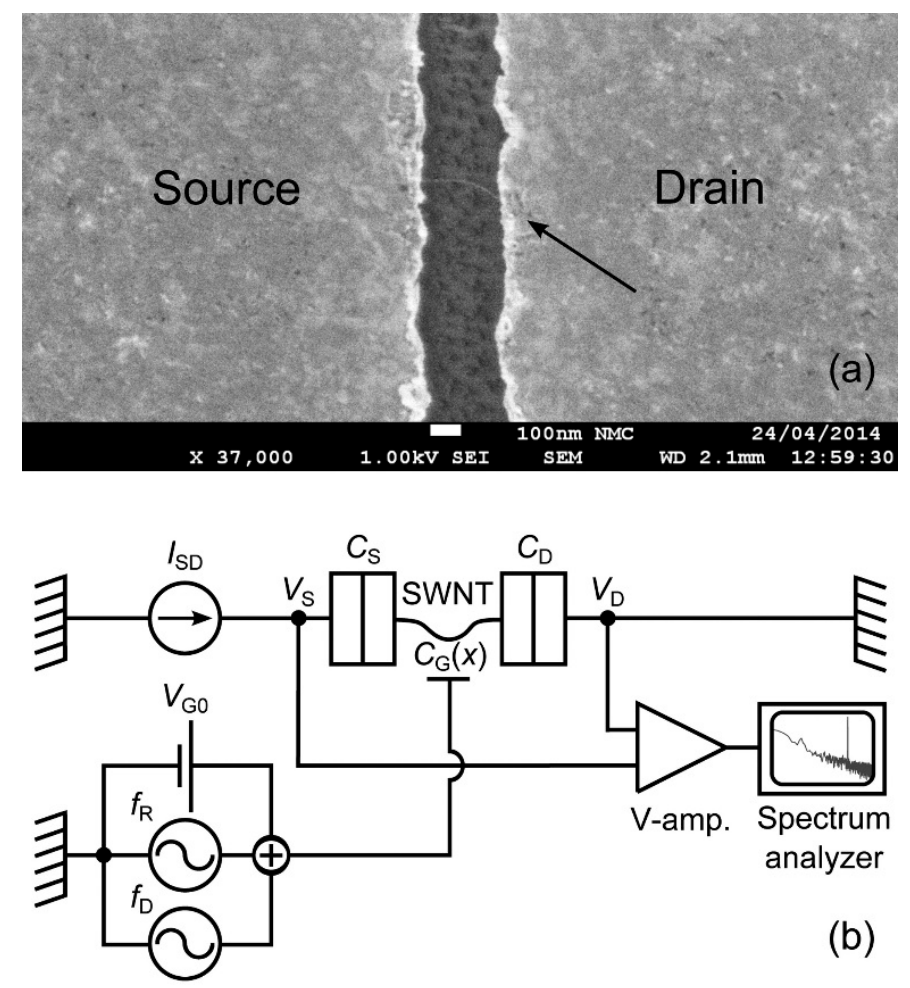

Figure 6. SWNT-SET NEMS resonant sensor (a) SEM image of device with a suspended CNT between source and drain electrodes (b) measurement setup [77]

Frequency stability is a key concern for the performance of nano-resonators and their applications. Frequency stability at the resonance frequency of these resonators can be affected by the noise added to the signal amplitude, which provokes jitters in the phase. This noise can induce spectral broadening and fluctuations in the resonance frequency. The 
resolution of the resonant sensors not only depends on the Q factor but also is limited by the dynamic range (DR). The relation between frequency stability $\left\langle\delta f / f_{0}\right\rangle$, Q factor and DR of the resonator device can be presented as $\left\langle\delta f / f_{0}\right\rangle=1 /(2 Q) \times 10^{-D R / 20}[78]$. Here, DR is expressed as the ratio between the maximum driven signal level and the noise floor $(\mathrm{dB})$. Based on this relation, we can conclude that higher Q factor and wider DR can improve the frequency stability.

Thus, one strategy to reduce phase noise is to increase Q factor. High Q factor of NEMS resonators can be achieved if the following major damping effects can be minimized: (1) thermoelastic damping (TED); (2) air damping due to the viscous drag or molecular collision; (3) anchor or clamping loss near the anchor of the resonator; (4) Akhiezer effect or loss; (5) phonon-tunneling dissipation; (6) surface loss due to surface imperfections [55], [57]. For instance, TED can be alleviated if the device size is reduced, and it is more prevalent in MEMS devices. However, design optimization is required for NEMS resonators so that downscaled resonator elements do not exhibit nonlinearity during sensing; the sensors can be operated at low pressure to avoid air damping to attain high Q; the clamping loss of [76] could be reduced if suspended element is designed for in-plane motion rather than out-ofplane motion. One promising way of increasing Q factor artificially in NEMS resonators is to introduce parametric amplification [69].

Another strategy to reduce the phase noise is to increase the dynamic range by minimizing the noises in the overall system. Independent multiple noise sources, categorized as extrinsic noises and intrinsic noises, contribute to the phase noise degradation of high-resolution resonant charge sensors. Intrinsic phase noise sources include thermomechanical noise contributed from random Brownian motion, adsorption-desorption noise, and temperature fluctuations due to the finite thermal conductance of the resonating device [79]. Thermomechanical force spectral density of NEMS resonator (per unit bandwidth) can be expressed as $S_{F}=\left(4 M_{\text {eff }} \omega_{0} K_{B} T\right) / Q$ [76]. Here, the ultimate limit on the force resolution $S_{F}$ is proportional to the temperature $T$ and inversely proportional to the $\mathrm{Q}$ factor. Therefore, low temperature and high $\mathrm{Q}$ are desirable to reduce the intrinsic phase noise. However, extrinsic noises arising from read-out circuitries are more dominant compared to the intrinsic noises in the sensing systems. For example, voltage and current noises in the pre-amplifier and corresponding biasing and gain components in [66] could exhibit significant noise magnitude at room temperature. Due to these setbacks of low $Q$ factor and high noise, the 
aforementioned NEMS resonators as charge sensors are preferred to operating at cryogenic temperature and very low pressure to achieve high charge resolution.

\subsection{MEMS based resonant electrometer}

The advent of micromachining and micro-electromechanical system (MEMS) technologies over four decades has enabled the development of various types of reduced sized sensors. Among these, the micromechanical resonant sensors have exquisite sensitivity and resolution. These sensors are used to manage a wide range of measurands, such as acceleration, density, mass, force, displacement, temperature, strain as well as the electrostatic charge [80]-[87].

Lee et al. designed a resonant MEMS based electrometer using the principle of axial strain modulation and a single-crystal silicon double-ended tuning fork (DETF) resonator as a charge-sensing element, as shown in figure 7 [88]. While the measurand (i.e. the charge) is coupled as an axial force along the longitudinal axis of the DETF, a charge across an input capacitor induces a tensile axial strain in the resonating tines (or parallel beams) resulting in a shift in resonant frequency. As shown in figure 7(a), one end of the DETF is anchored and the other end is physically constrained in the horizontal axis. To avoid out-of-plane motion, lateral guiding beams are located on each side. A charge actuation electrode is located adjacent to the free end of the DETF, forming the input of the electrometer. The tines are driven laterally in the anti-phase through parallel gap actuation electrodes attached on each tine. As the tines are forced into their primary mode of operation, the corresponding changes in the sense gaps generate a motional current at the sense electrodes, which is applied by transimpedance amplifier (TIA). For closed loop measurement setup of the electrometer, the TIA is followed by an active bandpass filter and a comparator forming a nonlinear oscillator circuit topology, which is capable of sustaining oscillations within large feedthrough limits. Both actuation and detection has been realized capacitively. In this electrometer, a minimum measurable charge of $4 \mathrm{fC}$ has been achieved at room temperature. This sensor's high sensitivity performance is due to a high $\mathrm{Q}$ factor of 80,000 at room temperature and a very low pressure of 4 mTorr. By using a balanced mode structure like DETF, the sensor significantly alleviates clamping loss to enhance the Q factor, thus the DETF structure is popular for designing a resonator based electrometer [88]-[89]. The resonant sensor was 
fabricated through a commercial silicon-on-insulator (SOI)-MUMPS foundry process from MEMSCAP [90].

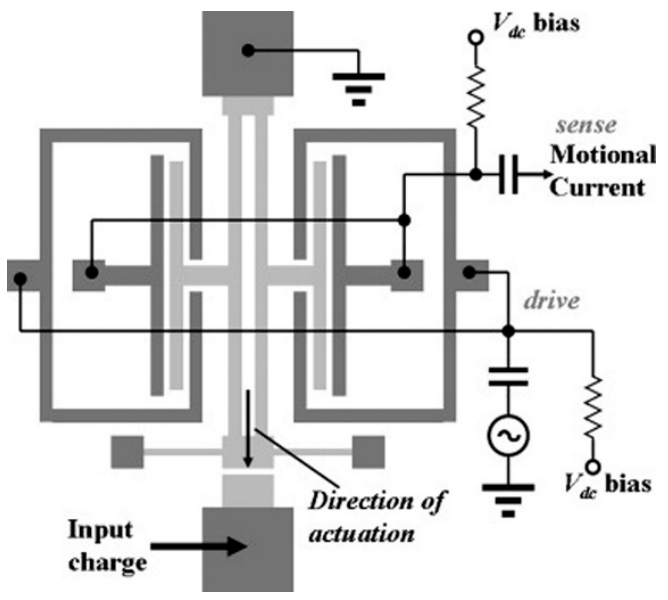

(a)

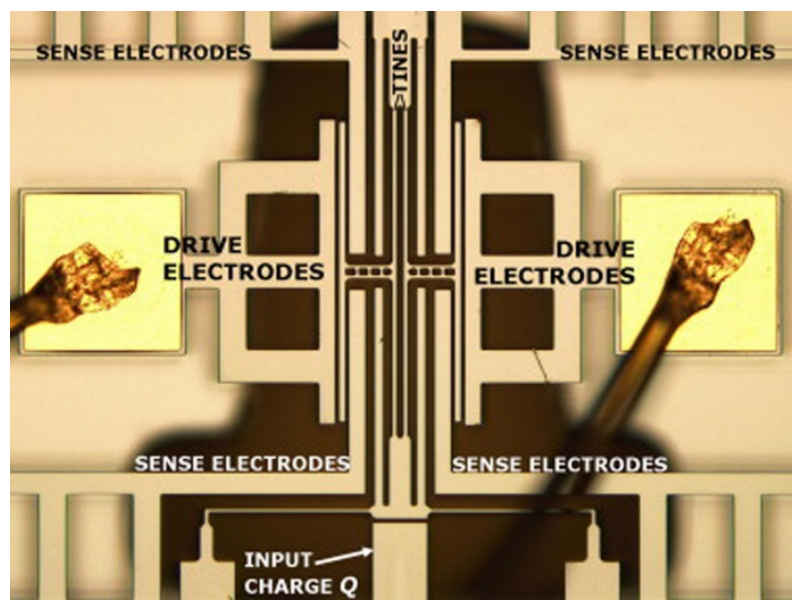

(b)

Figure 7. Single DETF resonator based MEMS electrometer (a) schematic diagram with open-loop measurement setup (b) scanning-electron micrograph image [88]

The responsiveness of the silicon DETF resonator could also be enhanced through mechanical force leverage systems, i.e. micro-leverage mechanisms (micro-levers) capable of amplifying an input force, as shown in figure 8 [91]. Utilizing the similar design principle of [88], dual micro-levers are exploited to enhance the sensitivity by the mechanical amplification. This mechanical amplifier neither adds significant Brownian noise nor influences the electronic noise level of the interface circuitry. The measured responsiveness of this electrometer has been achieved at $1.3 \times 10^{-3} \mathrm{~Hz} / \mathrm{fC}^{2}$. The resolution of the proposed charge sensor is $21 \mathrm{fC}$ under $4 \mathrm{ppm}$ frequency fluctuations. Zhao et al. further investigated this sensor by adding an adjustable or calibrated MEMS capacitor near the input charge electrode to achieve a high charge resolution of $0.84 \mathrm{fC}$ and a large dynamic range [92]. Both of these single crystal Si-resonant charge sensors were fabricated by the SOIMUMPs commercial process. Though sensing paradigms of [91] and [92] have key advantages, such as easy implementation and high resolution, DC bias (or tuning) voltages are comparably larger than [88] in these electrometry techniques. Moreover, these measurement setups have been implemented for open-loop systems rather than closed-loop systems. In measurement setups, the variable frequencies (of actuation signal) were produced by a network analyzer (figure 8(a)). Then, TIA amplified and converted the motional current to the voltage, and finally voltage signal fed to the same network analyzer. The performance of these types of 
resonant MEMS charge sensors is also limited by extrinsic phase noise (due to readout circuit) and intrinsic phase noise (such as temperature fluctuation noise, gas desorption and adsorption noise), significantly affecting both the short and long-term frequency stability.

Previously mentioned resonator based MEMS/NEMS charge sensors except ref [88] require the support of an external oscillator to compensate for energy losses; otherwise, these resonators will gradually stop oscillating. By exploiting an electronic feedback loop including an amplifier, filter, phase shifter and amplitude limiter, a closed-loop self-sustaining MEMS/NEMS oscillator can be obtained without using an external oscillator. Using closedloop measurement to track the resonance frequency of the resonators can achieve high frequency resolution and dynamic range compared to open-loop methods (such as frequency sweep, amplitude or phase-shift variation). Like NEMS resonator based sensing devices, the resolution of MEMS sensing system also suffers mainly due to electronic noises (white noise and flicker noise) of the readout circuits compared to the intrinsic noises. Phase noise is the crucial indicator of the total noise level in an oscillator and related to the resolution. In a Leeson-type model for an oscillator, the phase noise, $\mathcal{L}(f)$ is written as [93]

$$
\mathcal{L}(f)=10 \log \left\{\left(\frac{2 F_{n} k_{B} T}{P_{c}}\right) \cdot\left[1+\left(\frac{f_{0}}{2 Q f}\right)^{2}\right] \cdot\left[1+\left(\frac{f_{1 / f^{3}}}{f}\right)\right]\right\}
$$

where, $f$ is the frequency offset from the carrier resonance frequency $f_{0}, f_{1 / f^{3}}$ is corner offset frequency of the active devices used in the oscillator, $P_{C}$ is the carrier signal power; $F_{n}$ is noise factor of the active devices, $k_{B}$ is Boltzmann's constant, $T$ is absolute temperature in degrees Kelvin.

According to the equation (2), there are a few strategies to obtain lower phase noise in the MEMS resonator based self-sustaining oscillator, for example, higher $\mathrm{Q}$ factor, lower resonance frequency, higher carrier output power and lower temperature. In addition, by reducing flicker noise up-conversion and white noise (total root sum square of uncorrelated shot noise and Johnson noise) of the electronic circuitries, better phase noise performance can be achieved. Furthermore, the phase noise in [88] can be improved by synchronizing the nonlinear oscillator (in which resonant MEMS charge sensor is embedded) with the help of a weak external harmonic signal [94]. 


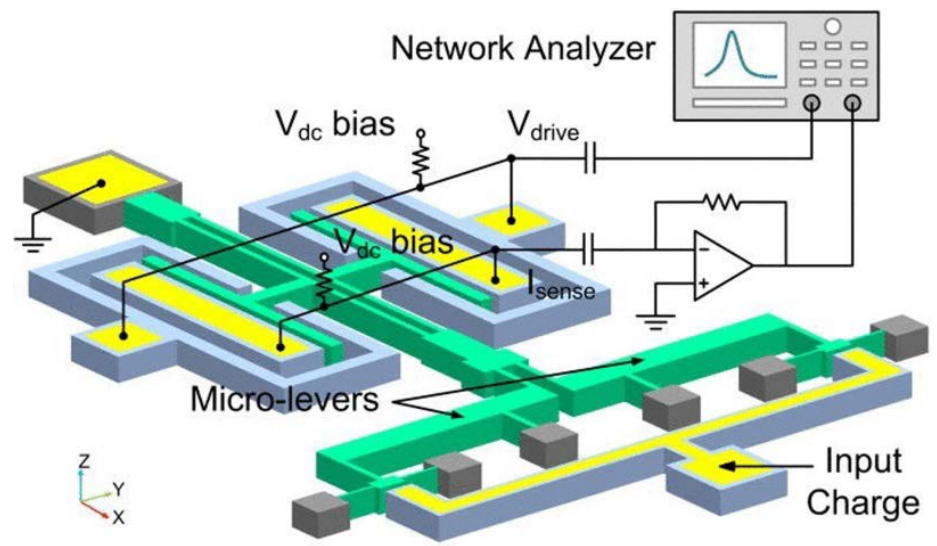

(a)
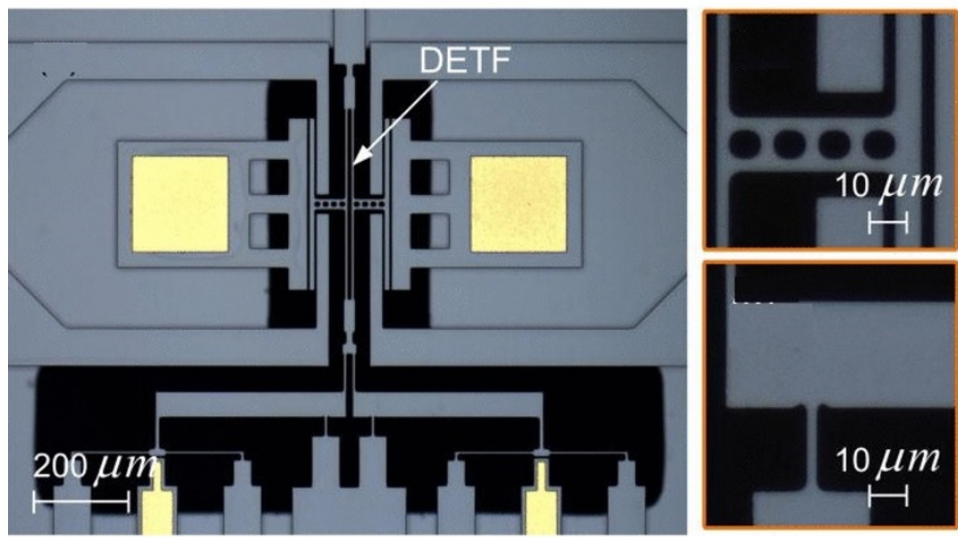

(b)

Figure 8. Single DETF resonator type MEMS electrometer with micro-leverage mechanism (a) schematic diagram with open-loop measurement setup (b) scanning-electron micrograph image [92]

Micromechanical resonant electrometers can be implemented not only by the single resonators but also the mode localization coupled resonators. Mode-localized resonator based electrometers utilize weakly coupled resonators (WCRs), which can be formed either electrostatically or mechanically [95]-[96]. Mode localization phenomenon is realized in a periodic system i.e. nearly identical WCRs. The presence of a small perturbation in the initially balanced system of WCRs prevents the long-range propagation of vibration. The tiny symmetry breaking perturbation of the structure causes extreme vibration of energy confinement. The vibration depends on both the magnitude of the induced order and the strength of the internal coupling between the WCRs. This weakly coupling between the resonators results in strong localization of the vibration modes. 
Thiruvenkatanathan et al. proposed the first 2-DOF electrically coupled mode localization MEMS electrometer, in which eigen-state or amplitude ratio was chosen as the output metric, and high sensitivity was achieved [97]. In the design, two electrostatically weakly coupled DETF resonators were used as a charge sensing element. Based on this principle, Zhang et al. modified the charge sensing element, in which a pair of DETF resonators was weakly coupled by a mechanical beam, as shown in figure 9(a) [98]-[99]. By decreasing mechanical coupling factor, the sensitivity of the sensor was increased, and thus better charge resolution of $1.269 \mathrm{fC}$ was achieved at temperature of $300 \mathrm{~K}$ and pressure of 20 mTorr [99]. Only the out-of-phase mode of each DETF resonator has been detected by placing the sensing electrodes in the centre of the two vibration tines (figure 9(b)). To adjust the effective stiffness of the two DETF resonators, four tuning electrodes around the two resonators are utilized. Two charge input electrodes are located adjacent to one end of resonator 2 forming a couple of charge actuation capacitors. When an external charge is applied to the charge input electrodes, the electrostatic strain acts on the resonator 2, and the effective stiffness of this resonator 2 will be altered. On the other hand, the resonator 1 will remain unchanged because of the absence of input charge. This is how breaking the initial symmetry occurs, and it causes the phenomenon of the mode localization. Finally, measurement of charge resolution can be obtained by measuring the variations of the amplitude ratios of the WCRs. This charge sensor was developed in SOI technology.

The mode-localized resonance principle can improve the sensor's sensitivity in comparison with conventional single resonant sensors. Moreover, owing to the differential configuration, this type of resonator has common mode rejection abilities. However, implementation of mode-localized charge sensors in a self-oscillating loop is a challenging issue. For all modelocalized sensors, the frequency of the actuation signal has to be adjusted locating the vibrational modes, and it is not practical in the sensory applications. It is also imperative to reduce the fluctuations of signal amplitude for the improvement of the sensor's resolution. Furthermore, geometry of the sensor device, the fabrication process, reduction of noise in the readout circuit and the measurement setup need to be improved for high resolution of modelocalized based resonant MEMS charge sensors. 


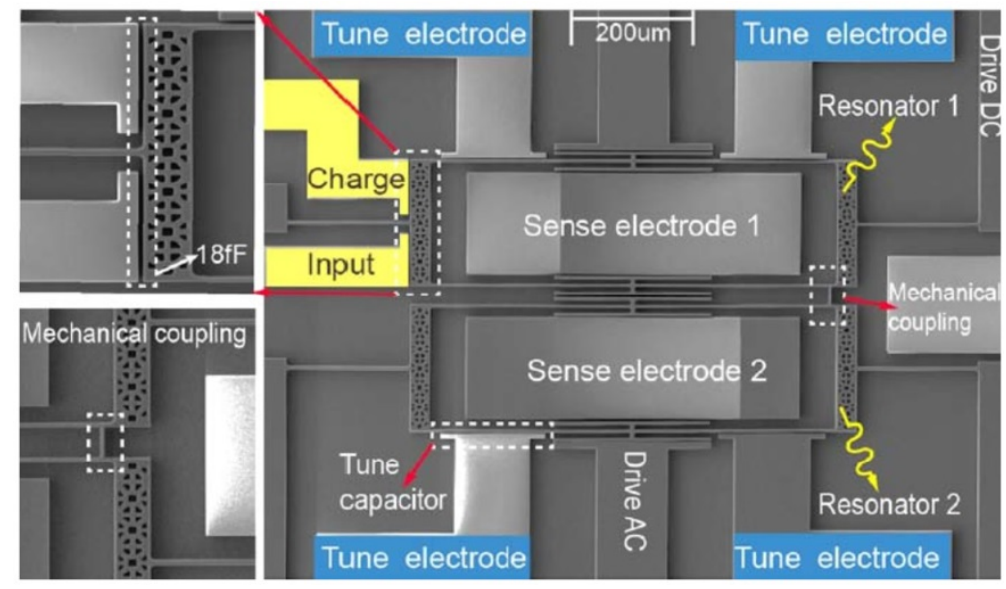

(a)

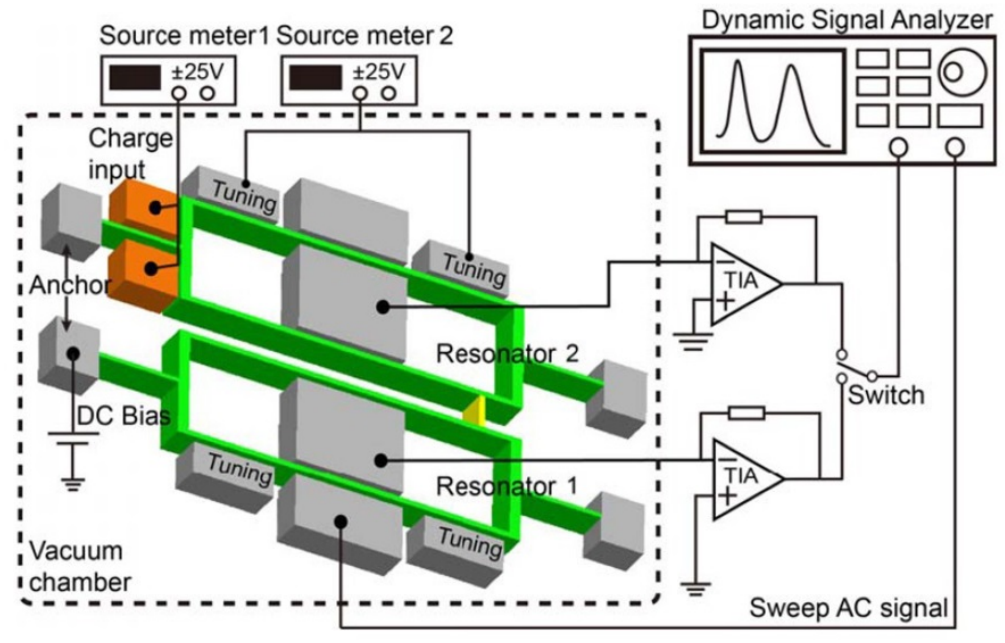

(b)

Figure 9. Mode-localized DETF resonator type MEMS electrometer (a) scanning-electron micrograph image (b) schematic diagram with open-loop measurement setup [99]

\section{Vibrating-reed Electrometer}

To avoid flicker noise at low frequencies or near DC levels, a vibrating-reed (vibratingcapacitor) electrometer is a suitable alternative to the previously discussed charge sensors [100]-[104]. In a MEMS vibrating-reed electrometer, a mechanical arrangement moves one of the two plates or comb drives of the dynamic-capacitor at a fixed frequency, $f_{m}$ [105]. This capacitor has been built between a moving electrode acting as a vibrating reed and a fixed input electrode. Typically, the electrodes can be either parallel plates or comb drives. When an external unknown amount of charge $q_{\text {in }}$ (or any small DC voltage representing the charge to be measured) is deposited on the parallel-plate immovable electrode, it is converted to an 
alternating voltage signal of frequency, $f_{m}$ as a consequence of the modulation of the resonating or dynamic-capacitor, $C_{v}$. In other words, capacitance of the resonating-capacitor is varied by some external force in a cyclic manner to produce an $\mathrm{AC}$ voltage $\left(\mathrm{V}_{\mathrm{AC}}\right)$ proportional to the charge on that capacitor, i.e. $q(t)=C_{V} \bullet V_{A C}$. Once the process has sufficiently amplified signal, a peak-detecting circuit, a synchronous demodulator (e.g. lockin amplifier), or some other circuit that measures the envelope of the modulation frequency and rejects the carrier, can turn the signal into a representation of the DC input charge. Due to the effect of charge feedthrough and flicker noise at low frequencies, the detection circuit is designed to operate at twice the drive frequency $\left(2 f_{m}\right)$.

Charge sensitivity detection by Reihl et al. employed a vibrating MEMS capacitance electrometer composed of an electrostatic comb drive actuator and sense parallel plate capacitors in ModMEMS process [106]. In the design, a charge resolution (charge noise floor) of approximately $28 \mathrm{e} / \sqrt{\mathrm{Hz}}$ was achieved at $300 \mathrm{~K}$ and in ambient pressure. One of the plates on a parallel plate capacitor is allowed to oscillate at a fixed frequency $(f)$, as shown in figure 10(a). This integrated-electrometer consists of three parts: differential actuators, differential motion detector, and charge modulation parallel-plate capacitors. An electrostatic charge collected in an electrode is modulated at the MEMS electrometer drive frequency and at higher harmonics, due to the nonlinear nature of parallel plate capacitors. Feedthrough interference from drive signals to the sensed charge is reduced by designing the charge capacitor $\left(\mathrm{C}_{\mathrm{c}}\right)$ and the detection electronics to measure a signal at twice the drive frequency (or some other multiple), where the feedthrough signal is minimized. This technique provides the benefit of separating the charge drive signal from the output signal, allowing for easy charge measurement. Designing such a CMOS-MEMS sensor device reduces parasitic effect significantly. An application specific IC (ASIC) as a buffer circuit has been introduced in the design with an input bias current of 5 atto-amperes. This circuit is a remedial of not to drain of the input charges by the bias current of the voltage gain amplifier. Nonetheless, under broad input range and various ranges of operating temperature, the bias current needs to be evaluated in this design for the correct measurement of charge resolution. 


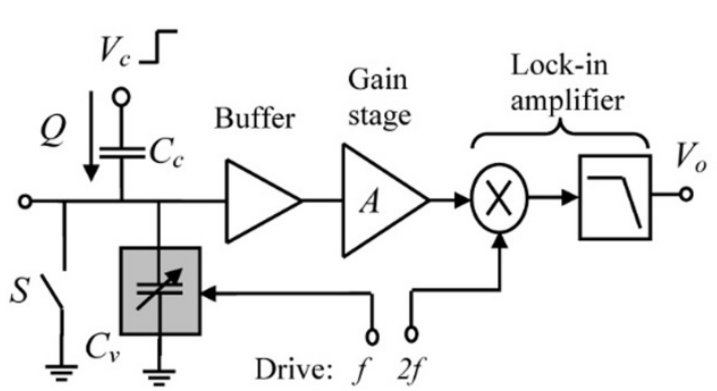

(a)

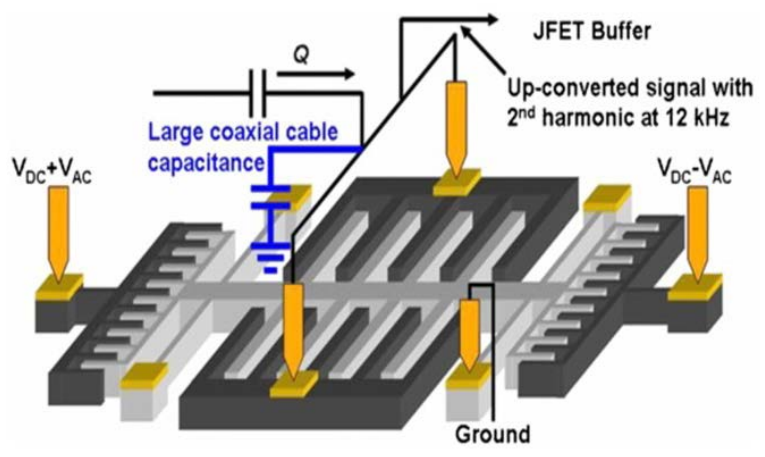

(c)

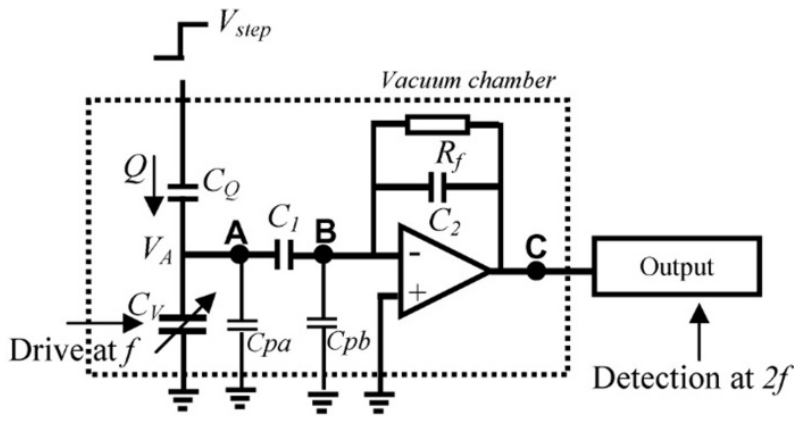

(b)

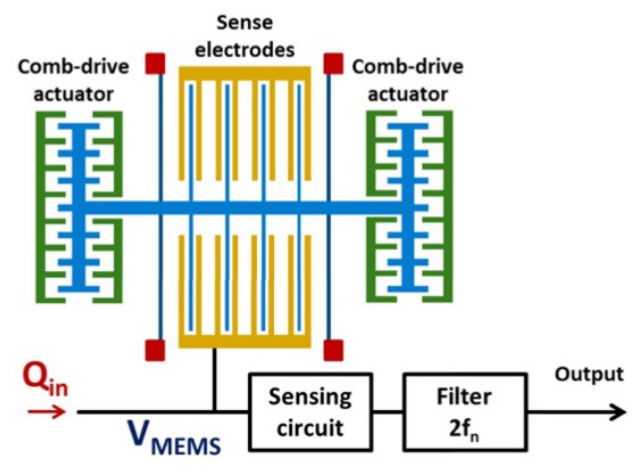

(d)

Figure 10. Different MEMS based vibrating-reed type charge sensing techniques [106]-[109]

Removing the buffer amplifier from the charge input node and replacing it with a capacitor to couple the input signal, Zhu et al. revealed a hybrid MEMS vibrating-reed electrometer [107]. The achievable charge resolution of the sensor is $52.4 \mathrm{e} / \sqrt{\mathrm{Hz}}$ (figure 10(b)). Another micro-machined hybrid vibrating-reed electrometer proposed by Lee et al. achieved a charge resolution of $6 \mathrm{e} / \mathrm{JHz}$ (figure 10(c)) [108]. Since the ultimate charge resolution of the electrometer is limited by the thermal electronic noise of the JFET input, a large responsiveness value is desirable in this demonstration. By altering the low noise readout amplifier to alleviate input-referred noise and parasitic capacitance, the sensitivity can be improved to achieve a resolution of $23 \mathrm{e} / \sqrt{ } \mathrm{Hz}$ for sensitive aerosol electromety applications, as shown in figure 10(d) [109]. One limitation of the vibrating-reed electrometry is the bandwidth by the presence of the large time constant at the input, i.e. it takes some time to respond adequately to the step function. Besides this shortcoming, the MEMS vibrating-reed 
electrometer has long-term drift and achievable high resolution in inexpensive design facilities of existing MEMS technologies.

MEMS vibrating reed sensing element along with the analog front-end readout circuits are main contributors of the total noise, which impedes achieving high charge resolution of the sensing system. The moving plate of the micromechanical variable capacitor is a mechanical resonator with a micro-meter scale range of motion modulating relatively small electrical signal. Mechanical noise is mainly thermomechanical or Brownian noise due to the random thermal motion of mechanical elements. The damping coefficient of Brownian noise at resonance frequencies of $5 \mathrm{kHz}$ to $10 \mathrm{kHz}$ yields a pico-meter range Brownian noise displacement, and thereby generating infinitesimal electrical signals. Thus, the pico-meter range motions of micromechanical variable capacitor due to Brownian motion have insignificant contribution for charge resolution limitation of these sensors. By contrast, the white noise and flicker noise in the signal conditioning circuitries can significantly deteriorate the charge resolution. Therefore, implementing low leakage current and noise readout amplifier will ensure high-resolution charge sensing capability.

\section{Summary and Perspectives}

Apart from charge resolution, the superiority of the charge sensor can be described based on the following features: (i) the sensor output instantaneously attains the sensed charge value, which provides for fast responsiveness; (ii) the charge in the sensor should not be distorted by itself to ensure impedance matching, i.e. avoiding loading effects; (iii) its output signal stays at the measured value without being affected by atmospheric and environmental effects, drifting, other noises and undesirable stimuli (unless the charge itself alters robustness and stability); (iv) low output impedance and high gain ensure high sensitivity and a sufficiently large output signal; (v) its output signal changes linearly in response to the input charge signal; (vi) the power dissipation should be insignificantly low due to the high input impedance. Table 1 shows a summary of empirical results of charge resolution measurements on different micro- and nano-sensors extracted from research papers.

Table 1. Performance comparison among various micro- and nano-charge sensor techniques 


\begin{tabular}{|c|c|c|c|c|c|c|c|}
\hline Ref. & $\begin{array}{c}\text { Charge } \\
\text { Sensing Type }\end{array}$ & $\begin{array}{c}\text { Transduction } \\
\text { Principle }\end{array}$ & $\begin{array}{l}\text { Functional } \\
\text { Materials }\end{array}$ & $\begin{array}{l}\text { Fabrication } \\
\text { Technology }\end{array}$ & Temperature & Pressure & Resolution \\
\hline [34] & $\overline{\text { DC SET }}$ & Tunneling & Aluminium & EBL & $25 \mathrm{mK}$ & - & $\begin{array}{c}8 \times 10^{-6} \\
\mathrm{e} / \sqrt{\mathrm{Hz}} @ 10 \\
\mathrm{~Hz}\end{array}$ \\
\hline [29] & RF-SET & $\begin{array}{c}\text { Tunneling } \\
+ \\
\text { Reflectometry }\end{array}$ & Aluminium & EBL & $4.2 \mathrm{~K}$ & - & $\begin{array}{c}1.2 \times 10^{-5} \\
\mathrm{e} / \sqrt{\mathrm{Hz}} \\
@ 100 \mathrm{MHz}\end{array}$ \\
\hline [38] & RF-SET & $\begin{array}{c}\text { Tunneling } \\
+ \\
\text { Reflectometry }\end{array}$ & Aluminium & $\begin{array}{l}\text { Std. lithography } \\
\text { and evaporation } \\
\text { technique }\end{array}$ & $4.2 \mathrm{~K}$ & - & $\begin{array}{c}1.9 \times 10^{-6} \\
\mathrm{e} / \sqrt{ } \mathrm{Hz} \\
@ 15 \mathrm{KHz}\end{array}$ \\
\hline [32] & RF-SET & $\begin{array}{c}\text { Tunneling } \\
+ \\
\text { Reflectometry }\end{array}$ & SWNT & $\begin{array}{l}\text { Std. lithography } \\
\text { and evaporation } \\
\text { technique }\end{array}$ & $4.2 \mathrm{~K}$ & - & $\begin{array}{l}4.8 \times 10^{-4} \\
\mathrm{e} / \sqrt{\mathrm{Hz}} \\
@ 30 \mathrm{~Hz}\end{array}$ \\
\hline [39] & RF-SET & $\begin{array}{c}\text { Tunneling } \\
+ \\
\text { Reflectometry }\end{array}$ & Silicon & EBL & $10 \mathrm{mK}$ & - & $\begin{array}{c}10 \times 10^{-6} \\
\mathrm{e} / \sqrt{\mathrm{Hz}} \\
@ 15 \mathrm{MHz}\end{array}$ \\
\hline [40] & RF-SET & $\begin{array}{c}\text { Tunneling } \\
+ \\
\text { Reflectometry }\end{array}$ & $\mathrm{Si} / \mathrm{SiGe}$ & $\begin{array}{c}\text { Shadow } \\
\text { evaporation } \\
\text { technique }\end{array}$ & $0.3 \mathrm{~K}$ & - & $\begin{array}{c}4 \times 10^{-6} \mathrm{e} / \sqrt{\mathrm{Hz}} \\
\text { @ } 1 \mathrm{kHz}\end{array}$ \\
\hline [45] & DC FET & Field Effect & Silicon & $\begin{array}{c}\text { Lithographic } \\
\text { patterning and } \\
\text { etching }\end{array}$ & $300 \mathrm{~K}$ & - & $\begin{array}{c}13 \times 10^{-4} \\
\mathrm{e} / \sqrt{\mathrm{Hz}} @ 1 \\
\mathrm{~Hz}\end{array}$ \\
\hline [46] & RF-FET & $\begin{array}{c}\text { Field Effect } \\
+ \\
\text { Reflectometry }\end{array}$ & Silicon & $\begin{array}{c}\text { Lithographic } \\
\text { patterning and } \\
\text { etching }\end{array}$ & $300 \mathrm{~K}$ & - & $\begin{array}{c}2 \times 10^{-4} \mathrm{e} / \sqrt{\mathrm{Hz}} \\
\text { @ } 20 \mathrm{MHz}\end{array}$ \\
\hline [66] & $\begin{array}{c}\text { NEMS } \\
\text { Torsional } \\
\text { resonator }\end{array}$ & $\begin{array}{l}\text { Magnetomotive } \\
\text { actuation and } \\
\text { detection }\end{array}$ & SOI & EBL & $4.2 \mathrm{~K}$ & $\begin{array}{l}\text { Vacuum } \\
(<\mathrm{mTorr}\end{array}$ & $10^{-6} \mathrm{e} / \sqrt{\mathrm{Hz}}$ \\
\hline [75] & $\begin{array}{c}\text { NEMS } \\
\text { Translational } \\
\text { resonator }\end{array}$ & $\begin{array}{l}\text { Magnetomotive } \\
\text { actuation and } \\
\text { detection }\end{array}$ & SOI & EBL+RIE & $4.2 \mathrm{~K}$ & $\begin{array}{c}1.3 \\
\text { Torr }\end{array}$ & $70 \mathrm{e} / \sqrt{\mathrm{Hz}}$ \\
\hline [76] & $\begin{array}{c}\text { NEMS } \\
\text { Translational } \\
\text { resonator }\end{array}$ & $\begin{array}{l}\text { Electrical/optical } \\
\text { actuation and } \\
\text { optical } \\
\text { interferometer } \\
\text { detection }\end{array}$ & Graphene & $\begin{array}{l}\text { Mechanical } \\
\text { exfoliating }\end{array}$ & $300 \mathrm{~K}$ & $<10^{-6}$ Torr & $\begin{array}{l}8 \times 10^{-4} \\
\mathrm{e} / \sqrt{\mathrm{Hz}}\end{array}$ \\
\hline [79] & $\begin{array}{c}\text { NEMS } \\
\text { Translational } \\
\text { resonator }\end{array}$ & $\begin{array}{l}\text { Electrostatic } \\
\text { actuation and } \\
\text { tunnelling } \\
\text { detection }\end{array}$ & SWNT & NEMS + SET & $50 \mathrm{mK}$ & - & $\begin{array}{c}0.97 \times 10^{-6} \\
\mathrm{e} / \sqrt{ } \mathrm{Hz}\end{array}$ \\
\hline [88] & $\begin{array}{c}\text { MEMS } \\
\text { Translational } \\
\text { resonator }\end{array}$ & $\begin{array}{c}\text { Electrostatic } \\
\text { actuation and } \\
\text { detection }\end{array}$ & SOI & $\begin{array}{c}\text { Bulk } \\
\text { Micromachining } \\
\text { (MEMSCAP) }\end{array}$ & $300 \mathrm{~K}$ & 4 mTorr & $4 \mathrm{fC}$ \\
\hline [91] & $\begin{array}{c}\text { MEMS } \\
\text { Translational } \\
\text { resonator }\end{array}$ & $\begin{array}{c}\text { Electrostatic } \\
\text { actuation and } \\
\text { detection }\end{array}$ & SOI & $\begin{array}{c}\text { Bulk } \\
\text { Micromachining } \\
\text { (MUMPS) }\end{array}$ & $300 \mathrm{~K}$ & 40 mTorr & $\begin{array}{l}21 \mathrm{fC} \text { under } 4 \\
\text { ppm } \\
\text { frequency } \\
\text { fluctuation }\end{array}$ \\
\hline
\end{tabular}




\begin{tabular}{|c|c|c|c|c|c|c|c|}
\hline [92] & $\begin{array}{c}\text { MEMS } \\
\text { Translational } \\
\text { resonator }\end{array}$ & $\begin{array}{c}\text { Electrostatic } \\
\text { actuation and } \\
\text { detection }\end{array}$ & SOI & $\begin{array}{c}\text { Bulk } \\
\text { Micromachining } \\
\text { (MUMPS) }\end{array}$ & $300 \mathrm{~K}$ & - & $0.84 \mathrm{fC}$ \\
\hline [99] & $\begin{array}{c}\text { MEMS } \\
\text { Weakly } \\
\text { coupled } \\
\text { resonator }\end{array}$ & $\begin{array}{c}\text { Electrostatic } \\
\text { actuation and } \\
\text { detection }\end{array}$ & SOI & $\begin{array}{c}\text { Surface } \\
\text { Micromachining }\end{array}$ & $300 \mathrm{~K}$ & 20 mTorr & $1.269 \mathrm{fC}$ \\
\hline [106] & $\begin{array}{c}\text { MEMS } \\
\text { Vibrating- } \\
\text { reed }\end{array}$ & $\begin{array}{c}\text { Electrostatic } \\
\text { actuation and } \\
\text { detection }\end{array}$ & SOI & $\begin{array}{c}\text { Surface } \\
\text { Micromachining } \\
\text { (ModMEMS) }\end{array}$ & $300 \mathrm{~K}$ & $\begin{array}{l}\text { Ambient } \\
\text { (Air) }\end{array}$ & $28 \mathrm{e} @ 0.3 \mathrm{~Hz}$ \\
\hline [107] & $\begin{array}{l}\text { MEMS } \\
\text { Vibrating- } \\
\text { reed }\end{array}$ & $\begin{array}{c}\text { Electrostatic } \\
\text { actuation and } \\
\text { detection }\end{array}$ & SOI & $\begin{array}{c}\text { Bulk } \\
\text { Micromachining } \\
\text { (MEMSCAP) }\end{array}$ & $300 \mathrm{~K}$ & $\begin{array}{l}\text { Ambient } \\
\text { (Air) }\end{array}$ & $52.4 \mathrm{e} / \sqrt{\mathrm{Hz}}$ \\
\hline [108] & $\begin{array}{c}\text { MEMS } \\
\text { Vibrating- } \\
\text { reed }\end{array}$ & $\begin{array}{c}\text { Electrostatic } \\
\text { actuation and } \\
\text { detection }\end{array}$ & SOI & $\begin{array}{c}\text { Bulk } \\
\text { Micromachining } \\
\text { (MEMSCAP) }\end{array}$ & $300 \mathrm{~K}$ & $\begin{array}{c}\text { Ambient } \\
\text { (Air) }\end{array}$ & $6 \mathrm{e} / \sqrt{\mathrm{Hz}}$ \\
\hline [109] & $\begin{array}{c}\text { MEMS } \\
\text { Vibrating- } \\
\text { reed }\end{array}$ & $\begin{array}{c}\text { Electrostatic } \\
\text { actuation and } \\
\text { detection }\end{array}$ & SOI & $\begin{array}{c}\text { Bulk } \\
\text { Micromachining } \\
\text { ( ThELMA) }\end{array}$ & $300 \mathrm{~K}$ & $\begin{array}{l}\text { Ambient } \\
\text { (Air) }\end{array}$ & $23 \mathrm{e} / \sqrt{\mathrm{Hz}}$ \\
\hline
\end{tabular}

There are continual scientific and technological interests in investigating minimum charge resolution mechanisms in various disciplines. The main objective of this article is to portray the micro and nano instrumentation features of the techniques used for the measurement of charge resolution and the corresponding design challenges of these techniques. The performance and prospects of recent MEMS based vibrating-reed charge sensors (at room temperature and ambient pressure) is superior to existing commercial macro-scale charge sensors in terms of the resolution; the low manufacturing costs in developed (but not standardized) semiconductor processes; their ability to be integrated with CMOS ICs; and their small packaging sizes [110]. In scaling down from MEMS to NEMS technology, the key challenging features are fabrication of the device, characterisation of the device and readout of the device. Owing to the limitations of micro-fabrication and the resolution concerns, established MEMS charge sensors cannot be scaled down suitably to the nano-scale range. In contrast, researchers around the globe are putting sustained efforts into using various materials and implementing novel fabrication technologies with fewer complications and better reproducibility for measuring the small fraction of electron charge (using the SET electrometer at room temperature). Even though nano-scale resonant charge sensors demonstrate the potential to overcome the resolution issue as compared to standalone SET electrometers (at room temperature), further research is needed to make resonant NEMS charge sensors practical by reducing noise and damping factor, in comparison with their MEMS counterparts. 


\section{References}

[1] Jaramillo G, Horsley D A, Buffa C and Langfelder G 2012 A MEMS based electrometer with a low-noise switched reset amplifier for charge measurement Proc. 11th IEEE Sensors Conf. (Taipei, Taiwan, October 2012) pp 1-4

[2] Barker R W J 1979 Modern electrometer techniques Proc. IEE 126 1053-68

[3] Taylor D M 2001 Measuring techniques for electrostatics J. Electrost. 51-52 502-8

[4] Horenstein M N and Stone P R 2001 A micro-aperture electrostatic field mill based on MEMS technology J. Electrost. 51-52 515-21

[5] Horenstein M N 1995 Measuring isolated surface charge with a noncontacting voltmeter J. Electrost. 35 203-13

[6] Hsu C H and Muller R S 1991 Micromechanical electrostatic voltmeter Transducers'91: IEEE Int. Conf. on Sensors and Actuators, Tech. Digest (San Francisco, CA, June 1991) pp 659-62

[7] Bahreyni B, Wijeweera G, Shafai C and Rajapakse A 2008 Analysis and design of a micromachined electric-field sensor J. Microelectromech. Syst. 17 31-36

[8] Vamivakas A N, Zhao Y, Fält S, Badolato A, Taylor J M and Atatüre M 2011 Nanoscale optical electrometer Phys. Rev. Lett. 107166802

[9] Taylor S, Tindall R F and Syms R R A 2001 Silicon based quadrupole mass spectrometry using microelectromechanical systems J. Vac. Sci. Technol. B 19 557-62

[10] Krueger F and Larson J 2002 Chipmunk IV: development of and experience with a new generation of radiation area monitors for accelerator applications Nucl. Instrum. Methods Phys. Res. A 495 20-28

[11] Matsusaka S, Maruyama H, Matsuyama T and Ghadiri M 2010 Triboelectric charging of powders: a review Chem. Eng. Sci. 65 5781-807

[12] Hana B, Huddaa N, Ninga Z, Kimb H J, Kimb Y J and Sioutas C 2009 A novel bipolar charger for submicron aerosol particles using carbon fiber ionizers J. Aerosol Sci. 40 285-94

[13] Chen Y P, Cox A J, Hagmann and Smith H D A 1996 Electrometer preamplifier for scanning tunneling microscopy Rev. Sci. Instrum. 67 2652-53

[14] Heer R, Eder C, Smoliner J and Gornik E 1997 Floating electrometer for scanning tunneling microscope applications in the femtoampere range Rev. Sci. Instrum. 68 4488-91 
[15] Park S S, Lee C J, Kim S W, Lee S B, Bae G N and Moon K C 2005 A novel ultrafine particle measurement system with an electrometer Proc. 48th Midwest Symposium on Circuits and Systems (Covington, KY, August 2005) 1 pp 227-30

[16] Menzel A, Lin A T H, Estrela P, Li P and Seshia A A 2011 Biomolecular and electrochemical charge detection by a micromechanical electrometer Sens. Actuator BChem. 160 301-305

[17] Calle C I, Mantovani J G, Buhler C R, Groop E E, Buehler M G and Nowicki A W 2004 Embedded electrostatic sensors for Mars exploration missions J. Electrost. 61 $245-57$

[18] Millikan R A 1911 The isolation of an ion, a precision measurement of its charge, and the correction of Stoke's law Phys. Rev. (Series I) 32 349-97

[19] Muller R H 1967 New sensitive vibrating reed electrometer Anal. Chem. 39 173A$176 \mathrm{~A}$

[20] Kucerovsky D and Kucerovsky V 2003 Analysis of the dynamic Faraday cup J. Phys. D: Appl. Phys. 36 2407-16

[21] Sosolik C E, Lavery A C, Dahl E B and Cooper B H 2000 A technique for accurate measurements of ion beam current density using a Faraday cup Rev. Sci. Instrum. 71 3326-30

[22] Low level measurements handbook 2004 Keithley (Cleveland 6th edition)

[23] Pallás-areny R and Webster J G 2001 Sensors and Signal Conditioning (New York: John Wiley \& Sons Inc.)

[24] Nishiguchi K, Ono Y and Fujiwara A 2014 Single-electron thermal noise Nanotechnology 25275201

[25] Averin D V and Likharev K K 1986 Coulomb blockade of single-electron tunneling, and coherent oscillations in small tunnel junctions J. Low Temp. Phys. 62 345-73

[26] Fulton T A and Dolan G J 1987 Observation of single-electron charging effects in small tunnel junctions Phys. Rev. Lett. 59 109-12

[27] Tilke A, Pescini L, Blick R H, Lorenz H and Kotthaus J P 2000 Single-electron tunneling in silicon nanostructures Appl. Phys. A 71 357-65

[28] Mar D J, Westervelt R M and Hopkins P F 1994 Cryogenic field-effect transistor with single electronic charge sensitivity Appl. Phys. Lett. 64 631-33

[29] Schoelkopf R J, Wahlgren P, Kozhevnikov A A, Delsing P and Prober D E 1998 The radio-frequency single-electron transistor (RF-SET): a fast and ultrasensitive electrometer Science 280 1238-42 
[30] Berman D, Zhitenev N B, Ashoori R C, Smith H I and Melloch M R 1997 Singleelectron transistor as a charge sensor for semiconductor applications J. Vac. Sci. Technol. B 15 2844-47

[31] Likharev K K 1999 Single electron devices and their applications Proc. IEEE 87 60632

[32] Tang Y, Amlani I, Orlov A O, Snider G L and Fay P J 2007 Operation of singlewalled carbon nanotube as a radio-frequency single-electron transistor Nanotechnology 18445203

[33] Wang L J, Cao G, Tu T, Li H O, Zhou C, Hao X J, Su Z, Guo G C, Jiang H W and Guo G P 2010 A graphene quantum dot with a single electron transistor as an integrated charge sensor Appl. Phys. Lett. 97262113

[34] Krupenin V A, Presnov D E, Zorin A B and Niemeyer M N 2000 Aluminium single electron transistors with islands isolated from the substrate J. Low Temp. Phys.118 287-96

[35] Hanke U and Galperin Y M and Chao K A 1994 Charge sensitivity of a single electron transistor Appl. Phys. Lett. 65 1847-1849

[36] Kafanov S, Brenning H, Duty T and Delsing P 2008 Charge noise in single-electron transistors and charge qubits may be caused by metallic grains Phys. Rev. B 78 $125411-17$

[37] Aassime A, Gunnarsson D, Bladh K, Delsing P and R.J. Schoelkopf 2001 Radiofrequency single-electron transistor: toward the shot-noise limit Appl. Phys. Lett. 79 4031-33

[38] Brenning H, Kafanov S, Duty T, Kubatkin T and Delsing P 2006 An ultrasensitive radio-frequency single-electron transistor working up to $4.2 \mathrm{~K}$ J. Appl. Phys. 100 114321

[39] Angus S J, Ferguson A J, Dzurak A S and Clark R G 2008 A silicon radio-frequency single electron transistor Appl. Phys. Lett. 92112103

[40] Yuan M, Yang Z, Savage D E, Lagally M G, Eriksson M A and Rimberg A J 2012 Charge sensing in a $\mathrm{Si} / \mathrm{SiGe}$ quantum dot with a radio frequency superconducting single-electron transistor Appl. Phys. Lett. 101142103

[41] Segall K, Lehnert K W, Stevenson T R, Schoelkopf R J, Wahlgren P, Aassime A and Delsing P 2002 A high-performance cryogenic amplifier based on a radio-frequency single electron transistor Appl. Phys. Lett. 81 4859-4861 
[42] Sun Y, Rusli and Singh N 2011 Room-temperature operation of silicon singleelectron transistor fabricated using optical lithography IEEE Trans. Nanotechnol. 10 96-98

[43] Rafiq M A, Masubuchi K, Durrani Z A K, Colli A, Mizuta H, Milne W I and Oda S 2012 Conduction bottleneck in silicon nanochain single electron transistors operating at room temperature Jpn. J. Appl. Phys. 51025202

[44]Zheng H, Asbahi M, Mukherjee S, Mathai C J, Gangopadhyay K, Yang J K, Gangopadhyay S 2015 Room temperature coulomb blockade effects in Au nanocluster/pentacene single electron transistors Nanotechnology 26355204

[45] Nishiguchi K, Koechlin C, Ono Y, Fujiwara A, Inokawa H and Yamaguchi H 2008 Single-electron-resolution electrometer based on field-effect transistor Jpn. J. Appl. Phys. 47 8305-10

[46] Nishiguchi K, Yamaguchi H, Fujiwara A, Zant H S J van der and Steele G A 2013 Wide-bandwidth charge sensitivity with a radio-frequency field-effect transistor Appl. Phys. Lett. 103143102

[47] Hadley P, Lientschnig G and Lai M J 2002 Single-electron transistors Compound Semiconductors 2002 Institute of Physics Conference Series (Proc.29th Int. Symp. Compound Semiconductors, Lausanne, Switzerland, October 2002) pp 125-32

[48] Mile E, Jourdan G, Bargatin I, Labarthe S, Marcoux C, Andreucci P, Hentz S, Kharrat C, Colinet E and Duraffourg L 2010 In-plane nanoelectromechanical resonators based on silicon nanowire piezoresistive detection Nanotechnology 21165504

[49] Hajhashemi M S, Rasouli A and Bahreyni B 2016 Improving sensitivity of resonant sensor systems through strong mechanical coupling J. Microelectromech. Syst. $2552-$ 59

[50] Arcamone J, Boogaart M A F van den, Serra-Graells F, Fraxedas J, Brugger J and Pérez-Murano F 2008 Full-wafer fabrication by nanostencil lithography of micro/nanomechanical mass sensors monolithically integrated with CMOS Nanotechnology 19305302

[51] Lee J E Y, Zhu Y and Seshia A A 2008 A bulk acoustic mode single-crystal silicon microresonator with a high-quality factor J. Micromech. Microeng. 18064001

[52] Schwab K C and Roukes M L 2005 Putting mechanics into quantum mechanics Phys. Today 58 36-42 
[53] Eom K, Park H S, Yoon D S and Kwon T 2011 Nanomechanical resonators and their applications in biological/chemical detection: nanomechanics principles Phys. Rep. 503 115-163

[54] Vidal-Álvarez G et al. 2015 Top-down silicon microcantilever with coupled bottomup silicon nanowire for enhanced mass resolution Nanotechnology 26145502

[55] Cimalla V, Niebelschutz F, Tonisch K, Foerster Ch, Brueckner K, Cimalla I, Friedrich T, Pezoldt J, Stephan R, Hein M and Ambacher O 2007 Nanoelectromechanical devices for sensing applications Sens. Actuator B-Chem. 126 24-34

[56] Wang Q and Arash B 2014 A review on applications of carbon nanotubes and graphenes as nano-resonator sensors Comp. Mater. Sci. 82 350-360

[57] Waggoner P S and Craighead H G 2007 Micro- and nano-mechanical sensors for environmental, chemical, and biological detection Lab Chip 7 1238-1255

[58] Barton R A, Ilic B, Zande A M van der, Whitney W S, McEuen P L, Parpia J M and Craighead H G 2011 High, size-dependent quality factor in an array of graphene mechanical resonators Nano Lett. 11 1232-1236

[59] Kim B, Hopcroft M A, Candler R N, Jha C M, Agarwal M, Melamud R, Chandorkar S A, Yama G and Kenny T W 2008 Temperature dependence of quality factor in MEMS resonators J. Microelectromech. Syst. 17 755-66

[60] Hu H, Cho H, Somnath S, Vakakis A F and King W P 2014 Silicon nano-mechanical resonators fabricated by using tip-based nanofabrication Nanotechnology 25275301

[61] Verbridge S S, Craighead H G and Parpia J M 2008 A megahertz nanomechanical resonator with room temperature quality factor over a million 2008 Appl. Phys. Lett. 92013112

[62] Venstra W J, Capener M J and Elliott S R 2014 Nanomechanical gas sensing with nonlinear resonant cantilevers Nanotechnology 25425501

[63] Jiang J W, Park H S and Rabczuk T 2012 Enhancing the mass sensitivity of graphene nanoresonators via nonlinear oscillations: the effective strain mechanism Nanotechnology 23475501

[64] Evoy S, Carr D W, Sekaric L, Olkhovets A, Parpia J M and Craighead H G 1999 Nanofabrication and electrostatic operation of single-crystal silicon paddle oscillators J. Appl. Phys. 86 6072-77

[65] Coulomb C A 1785 Premier mémoir sur l'eléctricité et le magnetism Mémoires de l'Academie Royale des Sciences pour l'Année 1788 569-577 
[66] Cleland A N and Roukes M L 1998 A nanometer-scale mechanical electrometer Nature 392 160-162

[67]Huang X M H, Zorman C A, Mehregany M and Roukes M L 2003 Nanoelectromechanical systems: nanodevice motion at microwave frequencies Nature $421496-496$

[68] Arlett J L, Myers E B and Roukes M L 2011 Comparative advantages of mechanical biosensors Nat. Nanotechnol. 6 203-215

[69] Kacem N, Hentz S, Pinto D, Reig B and Nguyen V 2009 Nonlinear dynamics of nanomechanical beam resonators: improving the performance of NEMS-based sensors Nanotechnology 20275501

[70] LaHaye M D, Buu O, Camarota B and Schwab K C 2004 Approaching the quantum limit of a nanomechanical resonator Science 304 74-77

[71] Craighead H G 2000 Nanoelectromechanical systems Science 290 1532-1535

[72] Hwang K S, Lee S M, Kim S K, Lee J H and Kim T S 2009 Micro-and nanocantilever devices and systems for biomolecule detection. Ann. Rev. Anal. Chem. 2 77-98

[73]Ekinci K L 2005 Electromechanical transducers at the nanoscale: actuation and sensing of motion in nanoelectromechanical systems (NEMS) Small 1 786-97

[74] Yasumura K Y, Stowe T D, Chow E M, Pfafman T, Kenny T W, Stipe B C and Rugar D 2000 Quality factors in micron- and submicron-thick cantilevers $J$. Microelectromech. Syst. 9 117-125

[75] Blick R H, Erbe A, Tilke A, Krömmer H, Pescini L, Manus S, Kriele A and Kotthaus J P 2000 Charge detection with nanomechanical resonators Physica E 6 821-827

[76] Bunch J S, Zande A M van der, Verbridge S S, Frank I W, Tanenbaum D M, Parpia J M, Craighead H G and McEuen P L 2007 Electromechanical resonators from graphene sheets Science 315 490-493

[77] Häkkinen P, Isacsson A, Savin A, Sulkko J and Hakonen P 2015 Charge sensitivity enhancement via mechanical oscillation in suspended carbon nanotube devices Nano Lett. 15 1667-1672

[78] Ekinci K L, Yang Y T and Roukes M L 2004 Ultimate limits to inertial mass sensing based upon nanoelectromechanical systems J. App. Phys. 95 2682-2689

[79] Cleland A N and Roukes M L 2002 Noise processes in nanomechanical resonators $J$. App. Phys 92 2758-2769 
[80] Etchart I, Chen H, Dryden P, Jundt J, Harrison C, Hsu K, Marty F and Mercier B 2008 MEMS sensors for density-viscosity sensing in a low-flow microfluidic environment Sens. Actuator A-Phys. 141 266-275

[81] Tocchio A, Caspani A and Langfelder G 2012 Mechanical and electronic amplitudelimiting techniques in a MEMS resonant accelerometer IEEE Sensors J. 12 1719-25

[82] Burg T P, Mirza A R, Milovic N, Tsau C H, Popescu G A, Foster J S and Manalis S R 2006 Vacuum-packaged suspended microchannel resonant mass sensor for biomolecular detection J. Microelectromech. Syst.15 1466-76

[83] Lee J E Y, Bahreyni B, Zhu Y and Seshia A A 2007 Ultrasensitive mass balance based on a bulk acoustic mode single-crystal silicon resonator Appl. Phys. Lett. 91 234103

[84] Barthod C, Teisseyre Y, Géhin C and Gautier G 2003 Resonant force sensor using a PLL electronic Sens. Actuator A-Phys. 104 143-150

[85] Azevedo R G, Jones D G, Jog A V, Jamshidi B, Myers D R, Chen L, Fu X, Mehregany M, Wijesundara M B J and Pisano A P 2007 A SiC MEMS resonant strain sensor for harsh environment applications IEEE Sensors J. 7 568-76

[86] Kose T, Azgin K and Akin T 2016 Design and fabrication of a high performance resonant MEMS temperature sensor J. Micromech. Microeng. 26045012

[87] Lee J E Y, Zhu Y and Seshia A A 2008 A micromechanical electrometer approaching single-electron charge resolution at room temperature Proc. IEEE 21st Int. Conf. MEMS (Tucson, Arizona, January 2008) pp 948-51

[88] Lee J E Y, Bahreyni B and Seshia A A 2008 An axial strain modulated double-ended tuning fork electrometer Sens. Actuator A-Phys. 148 395-400

[89] Hajhashemi M S and Bahreyni B 2012 A differential electrometer based on coupled microresonators Proc. 11th IEEE Sensors Conf. (Taipei, Taiwan, October 2012) pp 14

[90] SOIMUMPs process http://www.memscap.com (MEMSCAP Inc., Research Triangle Park, Durham, NC 27709, USA)

[91] Zhao J, Ding H and Xie J 2015 Electrostatic charge sensor based on a micromachined resonator with dual microlevers Appl. Phys. Lett. 106233505

[92] Zhao J, Ding H, Ni S, Fu L, Wang W and Xie J 2016 High-resolution and large dynamic range electrometer with adjustable sensitivity based on micro resonator and electrostatic actuator Proc. IEEE 29th Int. Conf. MEMS (Shanghai, January 2016) pp 1074-77 
[93] Feng X L, White C J, Hajimiri A, Roukes M L 2008 A self-sustaining ultrahighfrequency nanoelectromechanical oscillator Nat. Nanotechnol. 3 342-346

[94] Shoshani O, Heywood D, Yang Y, Kenny T W and Shaw S W 2016 Phase noise reduction in an MEMS oscillator using a nonlinearly enhanced synchronization domain J. Microelectromech. Syst. 25 870-876

[95] Zhao C, Montaseri M H, Wood G S, Pu S H, Seshia A A and Kraft M 2016 A review on MEMS coupled resonators for sensing applications utilizing mode localization Sens. Actuator A-Phys. 249 93-111

[96] Zhao C, Wood G S, Xie J, Chang H, Pu S H, Chong H M H and Kraft M 2015 A sensor for stiffness change sensing based on three weakly coupled resonators with enhanced sensitivity Proc. IEEE 28th Int. Conf. MEMS (Estoril, January 2015) pp 881-884

[97] Thiruvenkatanathan P, Yan J and Seshia A A 2010 Ultrasensitive mode localized micromechanical electrometer Proc. IEEE Int. Freq. Control Symp. (Newport Beach, CA, June 2010) pp 91-96

[98]Zhang H, Yuan W, Huang J, Li B and Chang H 2016 A high-sensitive resonant electrometer based on mode localization of the weakly coupled resonators Proc. IEEE 29th Int. Conf. MEMS ( Shanghai, January 2016) pp 87-90

[99]Zhang H, Yuan W, Huang J, Li B and Chang H 2016 A high-sensitivity micromechanical electrometer based on mode localization of two degree-of-freedom weakly coupled resonators J. Microelectromech. Syst. 25 937-946

[100] Model 401 vibrating reed electrometer 1969 Instrument Manual (Cary Instrum., Monrovia, CA)

[101]Paleosky H, Swank R K and Grenchik R 1947 Design of dynamic condenser electrometers Rev. Sci. Instrum.18 298-314

[102]Williams W R and Hawes R C 1963 Vibrating reed electrometers Instrum. Control Syst. 36 112-118

[103]Rietveld G and Brom H E V den 2007 Vibrating reed electrometer for accurate measurement of electrical currents below 10 pA IEEE Trans. Instr. Meas. 56 559-563

[104] Rietveld G 2013 Vibrating reed electrometer with attocoulomb charge resolution and subattoampere current resolution IEEE Trans. Instr. Meas. 62 192-198

[105]Zhu Y, Lee J and Seshia A 2007 System-level simulation of a micromachined electrometer using a time-domain variable capacitor circuit model J. Micromech. Microeng. 171059 
[106]Riehl P S, Scott K L, Muller R S, Howe R T and Yasaitis J A 2003 Electrostatic charge and field sensors based on micromechanical resonators J. Microelectromech. Syst. 12 577-89

[107]Zhu Y, Lee J E Y and Seshia A A 2008 A resonant micromachined electrostatic sensor IEEE Sensors J. 8 1499-1505

[108] Lee J, Zhu Y and Seshia A 2008 Room temperature electrometry with SUB-10 electron charge resolution J. Micromech. Microeng. 18025033

[109] Jaramillo G, Buffa C, Li M, Brechtel F J, Langfelder G and Horsley D A 2013 MEMS electrometer with femtoampere resolution for aerosol particulate measurements IEEE Sens. J. 13 2993-3000

[110] Fischer A C, Forsberg F, Lapisa M, Bleiker S J, Stemme G, Roxhed N and Niklaus F 2015 Integrating MEMS and ICs Microsystems \& Nanoengineering 115005 